Review Article

\title{
Therapeutic Modulation of Virus-Induced Oxidative Stress via the Nrf2-Dependent Antioxidative Pathway
}

\author{
Choongho Lee (iD) \\ College of Pharmacy, Dongguk University, Goyang 10326, Republic of Korea \\ Correspondence should be addressed to Choongho Lee; lkj640@gmail.com
}

Received 25 May 2018; Accepted 24 September 2018; Published 31 October 2018

Guest Editor: Rômulo Novaes

Copyright (C) 2018 Choongho Lee. This is an open access article distributed under the Creative Commons Attribution License, which permits unrestricted use, distribution, and reproduction in any medium, provided the original work is properly cited.

\begin{abstract}
Virus-induced oxidative stress plays a critical role in the viral life cycle as well as the pathogenesis of viral diseases. In response to reactive oxygen species (ROS) generation by a virus, a host cell activates an antioxidative defense system for its own protection. Particularly, a nuclear factor erythroid 2p45-related factor 2 (Nrf2) pathway works in a front-line for cytoprotection and detoxification. Recently, a series of studies suggested that a group of clinically relevant viruses have the capacity for positive and negative regulations of the Nrf2 pathway. This virus-induced modulation of the host antioxidative response turned out to be a crucial determinant for the progression of several viral diseases. In this review, virus-specific examples of positive and negative modulations of the Nrf2 pathway will be summarized first. Then a number of successful genetic and pharmacological manipulations of the Nrf2 pathway for suppression of the viral replication and the pathogenesis-associated oxidative damage will be discussed later. Understanding of the interplay between virus-induced oxidative stress and antioxidative host response will aid in the discovery of potential antiviral supplements for better management of viral diseases.
\end{abstract}

\section{Virus-Induced Oxidative Stress}

Utilization of oxygen as a final electron acceptor in the mitochondrial energy metabolism by a cell leads to inevitable generation of oxygenated byproducts. Due to their high reactivity, they are often referred to as "reactive oxygen species" (ROS). Typical examples of them include superoxide $\left(\mathrm{O}_{2}{ }^{-}\right)$, hydrogen peroxide $\left(\mathrm{H}_{2} \mathrm{O}_{2}\right)$, hydroxyl radical $\left(\mathrm{OH}^{-}\right)$, and singlet oxygen [1]. In general, most of ROS are considered harmful due to their cell-damaging effects. Therefore, a variety of cellular defensive measures are designed in place to control them. In general, oxidative stress is defined as an imbalance between prooxidant and antioxidant systems. The surplus amount of oxidative stress results in cellular damage due to the oxidation of various essential host macromolecules. A series of so-called "phase II cytoprotective and detoxifying enzymes" are in charge of a mission to serve as a cellular guardian. A different kind of microbial infections was also shown to be a strong inducer of oxidative stress [2-5]. Interestingly, this infection-initiated oxidative stress was demonstrated to play a key role in the activation of innate immunity to fight off pathogenic microbes $[6,7]$.
Therefore, proper management of cellular oxidative stress is an important cellular task not only for the preservation of its cellular components but also for the maintenance of a germ-free state in the host cell.

Understanding of the mutual interaction between a host and a virus is a prerequisite to developing an effective antiviral strategy to control viral infection. Due to its limited genome size, a virus has evolved a unique talent to take a full advantage of host cellular environments to its favor. This means that all the requirements necessary for the successful completion of a viral life cycle are completely satisfied at the expense of a variety of host metabolic processes. However, these virus-induced changes on a host cellular metabolism have to be in a tight control in order to minimize their potentially detrimental effects on the overall health of the infected host cell. Interestingly, a number of viruses were shown to induce oxidative stress on purpose to facilitate their replication inside the cell [8-14]. This virus-induced oxidative stress and its proper management by a host cell might be a perfect example to understand the harmonious balance between a host and a virus. As previously mentioned, several critical antiviral signaling pathways such as 
Toll-like receptor and interferon (IFN) pathways are initiated by infection-induced oxidative stress $[15,16]$. In addition, defective maintenance of an appropriate redox balance by a host cell has been shown to contribute to the viral pathogenesis, resulting in massive induction of the oxidative stressinduced cell death [17-19]. Basically, the imbalance between ROS production and antioxidant defense system is in a direct link with the disruption of normal cellular physiology [2022]. A growing number of papers have described this virusinduced oxidative stress as one of the major pathogenic mechanisms for inflammatory response and tissue injury by a viral infection $[23,24]$. Therefore, a better understanding of the relationship between virus-induced oxidative stress and antiviral response of a host cell will be a prerequisite for the development of an effective therapeutic strategy to combat various viral diseases.

\section{Activation of the Nrf2 Pathway as a Defensive Mechanism against Oxidative Stress}

In order to neutralize the deleterious effects of oxidative stress, mammalian cells established a unique antioxidative defense system. This system is designed to be turned off under a normal condition. However, upon encountering oxidative stress, an oxidant-sensitive molecule is activated and transcriptionally stimulate a series of genes responsible for cytoprotection and detoxification. Nuclear factor erythroid 2p45-related factor 2 (Nrf2) is a transcription factor, which has evolved for this purpose. It is one of the bestcharacterized antioxidative transcription factors with an oxidants/electrophile-sensor function [25]. This basic leucine zipper protein consists of six conserved Nrf2-ECH homology (Neh) domains [26]. Under normal condition, it forms a complex with Kelch-like ECH-associated protein 1 (KEAP1), a well-known negative regulator of Nrf2 [27]. Since KEAP1 serves as an adaptor protein for cullin-3-based E3 ubiquitin ligase, this dimeric Nrf2/KEAP1 complex subjects Nrf2 to constant ubiquitination and proteasomal degradation [28]. In regard to their oxidant-sensing mechanism, redoxsensitive twenty-five cysteine residues of KEAP1 were shown to play a key role in the regulation of the E3 ubiquitin ligase activity [29]. Basically, these cysteine residues are very susceptible to conjugation of a variety of ROS-inducing agents. Once conjugated, the KEAP1-mediated ubiquitination of Nrf2 was severely diminished [30]. This leads to liberation of Nrf2 from the KEAP1-mediated restraint. Once stabilized, Nrf2 is able to get inside the nucleus and form a complex with one of small Maf proteins and other coactivators. Then binding of this trimeric complex to the antioxidant response elements (AREs) in the promoter regions facilities transcription of a series of cytoprotective and detoxifying genes. Typical examples of these Nrf2-target genes include heme oxygenase-1 (HO-1), NAD(P)H quinone oxidoreductase-1 (NQO-1), glutamate cysteine ligase catalytic and regulatory subunits (GCLC and GCLM), glutathione S-transferase (GST), uridine diphosphate glucuronosyltransferase (UDPGT), superoxide dismutase (SOD), catalase (CAT), glucose 6 phosphate dehydrogenase (G6PD), and glutathione peroxidase-1 (GPx) (Figure 1) [31-34].

\section{Positive and Negative Regulations of the Nrf2 Pathway by Viruses}

A virus needs to express a number of nonstructural and structural proteins inside a host cell to support the viral genome replication and assembly of a new virion. Several viral proteins have been shown to be responsible for the production of various $\operatorname{ROS}[10,11,13,22,35-40]$. This virusinduced oxidative stress plays a central role not only in the successful completion of the viral life cycle but also in the overall viral pathogenesis $[20,35,41]$. However, too much oxidative stress will be a burden on the host cell. Therefore, a virus needs to keep oxidative stress in an optimal level, which should be high enough to support the viral metabolism and should not be too high enough to kill off a host cell. In a way to control the ROS level, a virus has evolved to gain the ability to manipulate the Nrf2 pathway to its favor. Many studies found examples of positive modulation of the Nrf2 pathway by virus-induced oxidative stress [42-48]. However, in some cases, a number of viruses were shown to actively suppress the Nrf2 pathway [20, 43, 49-53]. Here, I would like to introduce evidence of positive and negative modulations of the Nrf2 pathway by various clinically relevant viruses and their implications in the virally induced pathogenesis. Detailed effects of each virus on the ROS level, redox defense system, Nrf2, and its target genes are summarized in Table 1.

3.1. Moloney Murine Leukemia Virus ts1. Moloney murine leukemia virus (MoMuLV) ts1 is a mutant retrovirus used for the study of a progressive neurodegeneration induced by a human immunodeficiency virus (HIV) [54, 55]. Accumulation of an incorrectly processed viral envelop glycoprotein, pPr80env, the subsequent onset of ER stress, and the following oxidative stress-induced apoptosis of the infected microglia and astrocytes have been attributed to this virally induced neurodegeneration [56]. However, a selected population of infected astrocytes was able to survive the cytopathic effects of a viral infection [57]. Particularly, upregulation of the antioxidant defense system via activation of the Nrf2 pathway was suggested as a major mechanism for survival of the infected astrocytes [58]. In this report, a significant increase in the levels of Nrf2 and its transcriptional target genes including cell surface cysteine-glutamate antiporter $(\mathrm{xCT})$, glutamate cysteine ligase catalytic and regulatory subunits (GCLC and GCLM), and glutathione peroxidase (GPx) was observed in these cells. In addition, they were shown to harbor the enhanced amounts of redox defense-related proteins such as gamma-glutamyl transpeptidase $(\gamma$-GT) and catalase [58]. Overall, they were able to maintain much higher levels of intracellular glutathione (GSH) and cysteine relative to those uninfected [58]. Based on these observations, authors concluded that successful immobilization of the thiol redox defense system via a positive modulation of the Nrf2 pathway contributed to the survival of the infected astrocytes despite the cytotoxic effects of MoMuLV ts1 [58].

3.2. Human Immunodeficiency Virus Type 1. Human immunodeficiency virus type $1(\mathrm{HIV}-1)$ plays an etiological role in the development of acquired immunodeficiency syndrome 


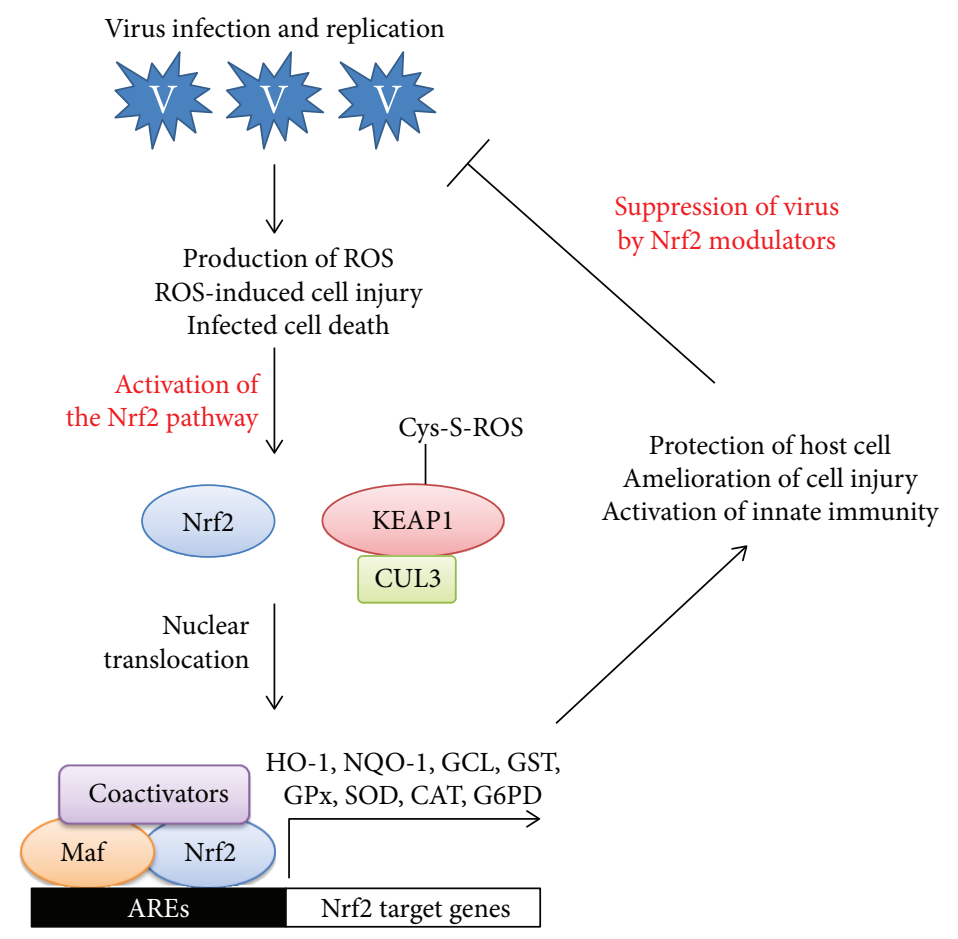

FiguRE 1: Induction of oxidative stress by a virus infection and genome replication. Subsequent activation of the Nrf2 pathway and amelioration of oxidative stress-induced cellular injury. Abbreviations used within the figure are as follows. Nrf2: nuclear factor erythroid 2-related factor 2; KEAP1: Kelch-like ECH-associated protein 1; CUL3: cullin-3; AREs: antioxidant response elements; HO-1: heme oxygenase-1; NQO-1: NAD(P)H quinone oxidoreductase-1; GCL: glutamate cysteine ligase; GST: glutathione; GPx: glutathione peroxidase; SOD: superoxide dismutase; CAT: catalase; G6PD: glucose 6 phosphate dehydrogenase.

(AIDS). Besides its immune-compromising effects, HIV-1 infection is also linked with the development of neurocognitive disorders $[59,60]$. Particularly, a viral gp120 protein was suggested to play a causative role in the HIV-1-associated neurodegeneration through induction of oxidative stress [8]. In response to this virus-induced oxidative stress, the Nrf2 pathway was found to be activated, leading to the expression of a series of the Nrf2-dependent antioxidant response genes including HO-1 and NQO-1 [8]. Pretreatment with both antioxidants and a calcium chelator antagonized this gp120-induced Nrf2 activation, further implicating the active involvement of oxidative stress and calcium signaling in mounting an antioxidative defense measure [8]. Based on these observations, the Nrf2 pathway was suggested to play a protective role in promoting survival of the HIVinfected astrocytes [8].

In addition to the gp120, one of three regulatory viral genes, a Tat protein also has been shown to be responsible for induction of oxidative stress upon HIV-1 infection [6164]. In regard to one of the potential mechanisms for the Tat-induced oxidative stress, a direct involvement of the Nmethyl-D-aspartate (NMDA) receptor and spermine oxidase (SMO) was proposed [65]. In this report, stimulation of the NMDA receptor by Tat and the subsequently accelerated catalysis of spermine into spermidine by SMO were suggested as the main mechanism for an increased production of $\mathrm{H}_{2} \mathrm{O}_{2}$ [65]. This, in turn, stabilized $\mathrm{Nrf} 2$ and transactivated the Nrf2 target genes such as NQO-1, CAT, SOD1, and HO-1 [65]. These series of cytoprotective protein and enzymes ultimately prevented the HIV-1 Tat-induced cell death [65]. Based on these findings, the Nrf2 pathway was proposed as an important determinant for protection against HIV-1induced neurodegeneration [65].

The pulmonary complication is one of the leading causes of death by HIV patients [66]. In particular, HIV-1 transgene expression was shown to significantly impair alveolar macrophage phagocytic capacity in the HIV-1 transgenic rats [67]. In relation to this observation, HIV-1 gp120 and Tat were identified as causative agents for oxidative stress and glutathione depletion by HIV-1 infection [38]. However, contrary to previous reports, Nrf2 expression was decreased in alveolar epithelial cells from HIV-1 transgenic rats compared with their wild-type counterparts [68]. This diminished expression of Nrf2 further increased epithelial barrier permeability and decreased transepithelial electrical resistance in HIV-1 transgenic rats [51]. Suppression of the Nrf2 pathway was also detected in human monocyte-derived macrophages either infected with HIV-1 or exposed to HIV-related proteins [53]. In line with this observation, accelerated aging by HIV-1 infection was noticed in the HIV-1 transgenic rats [50]. In these HIV-1 transgenic rats, a significant reduction in the protein levels of Nrf2 and HO-1 was also confirmed [50]. This further implicates the redox imbalance induced by expression of HIV-1 transgenes as a causative for the promotion of senescence in the transgenic rats [50]. Based on these findings, the use of Nrf2 activators was suggested as a promising approach to enhance lung innate immunity in HIV patients [53]. 


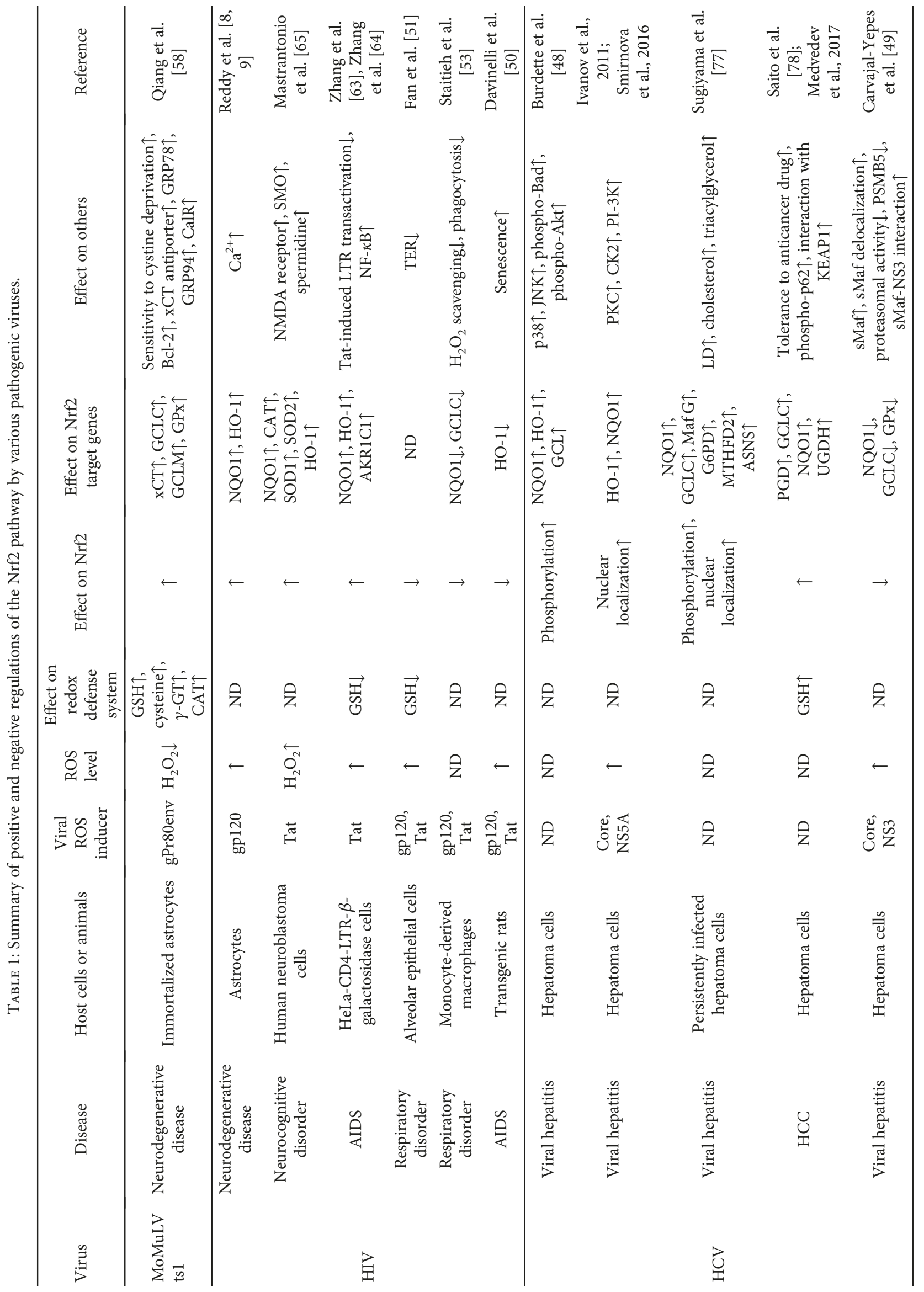




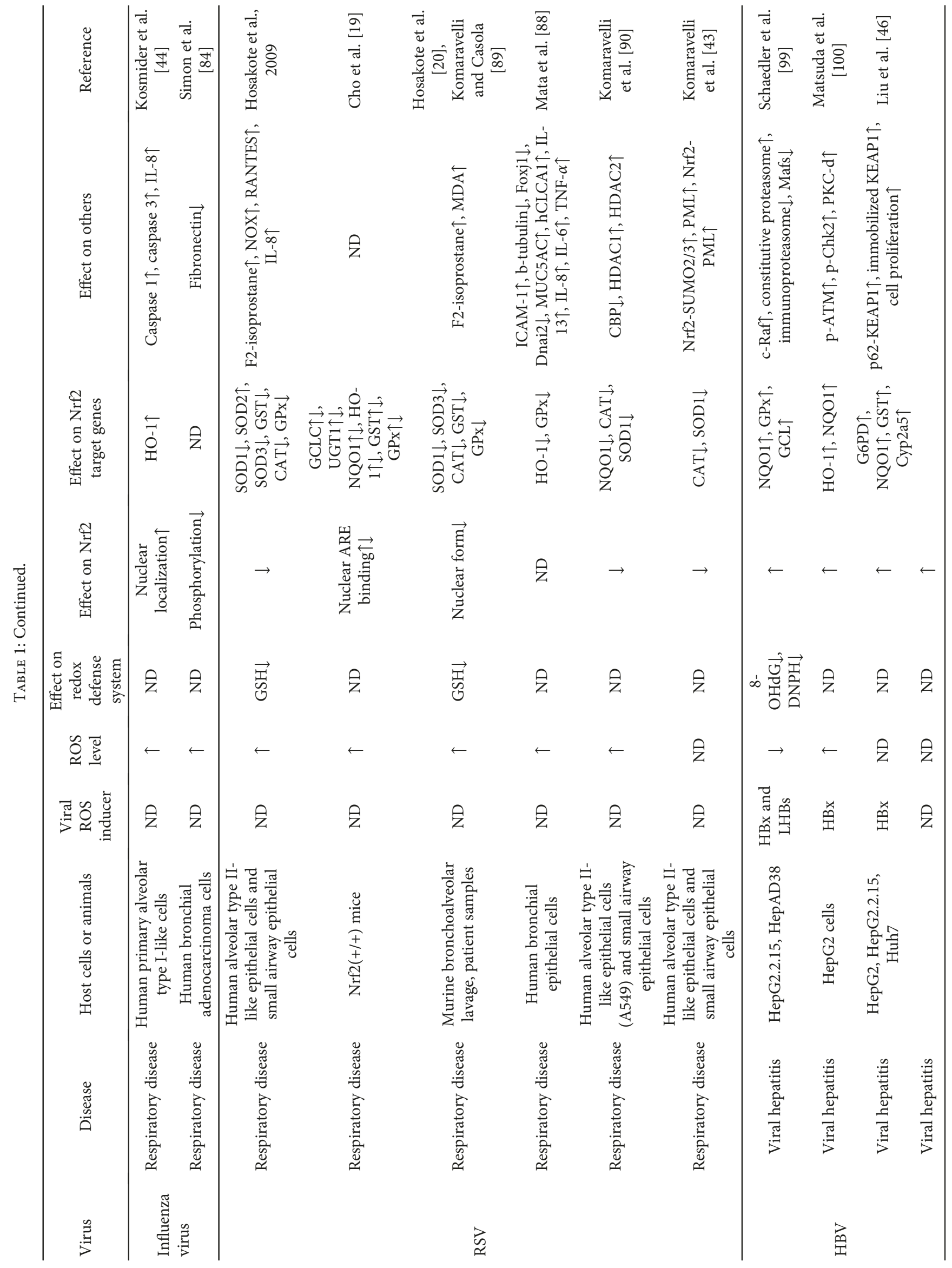




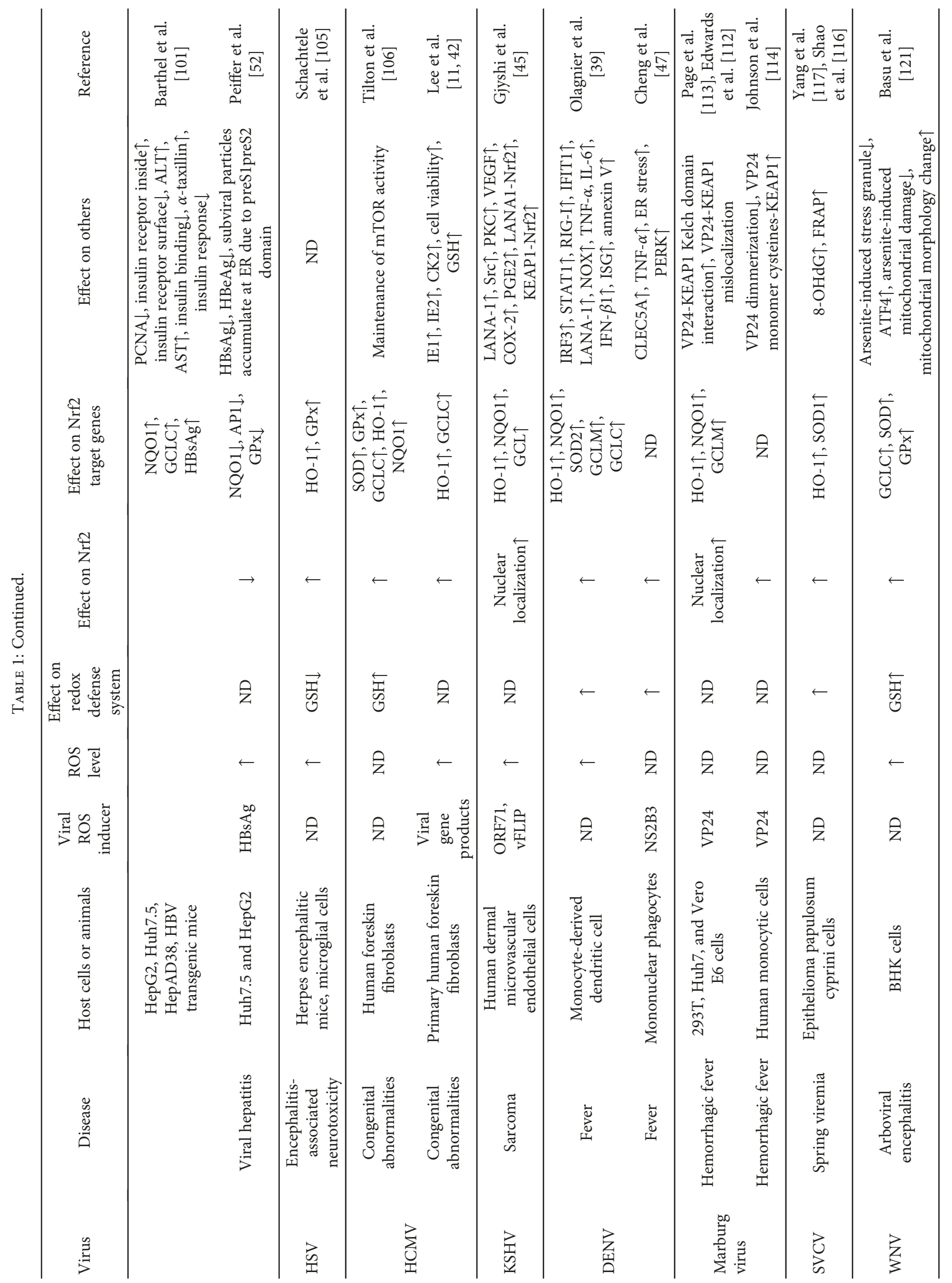




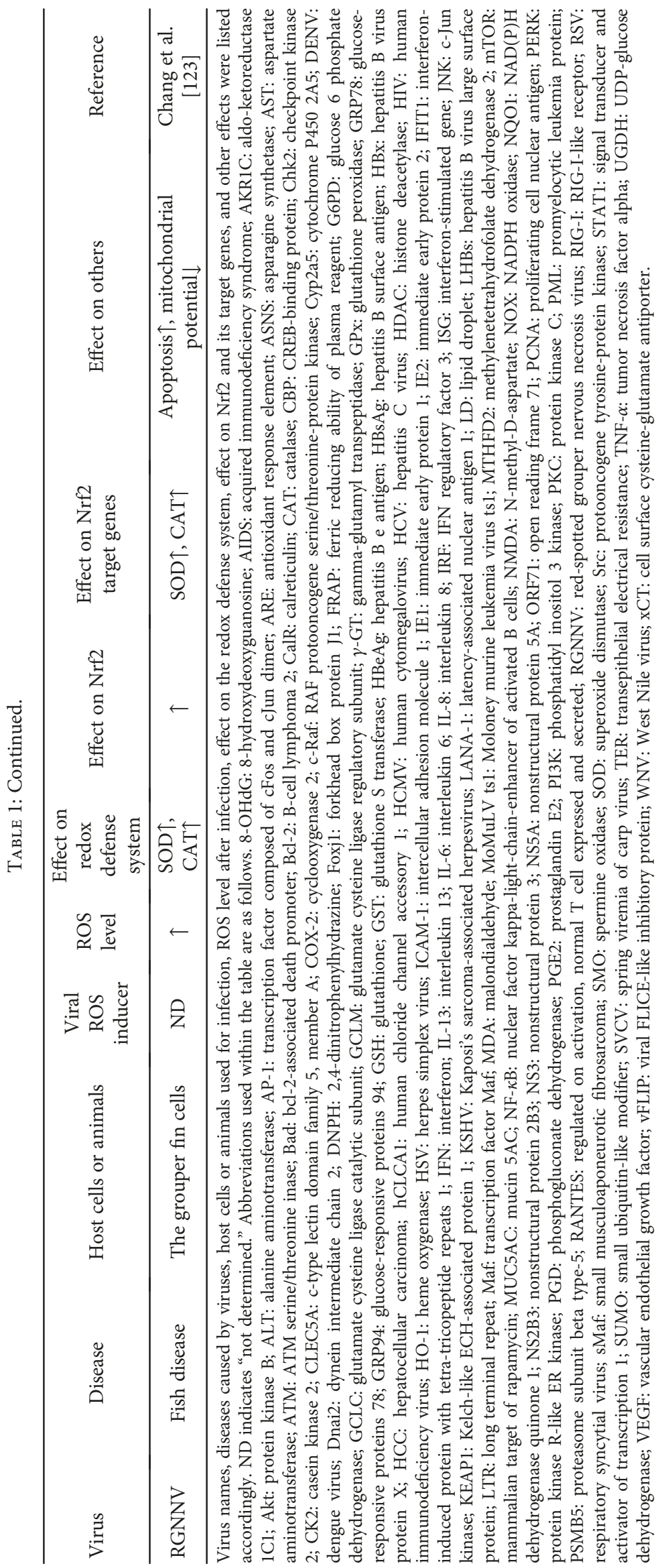


Transcriptional regulation of HIV-1 genes is controlled by a distinct viral enhancer and promoter called "long terminal repeats" (LTRs). A variety of host and viral transcriptional factors bind this region in a concerted manner to ensure a fine-tuning of viral gene expression. Particularly, Tat was shown to play an essential role in a positive regulation of the LTR-dependent transcription of viral genes [61]. Together with gp120, Tat is one of two main players responsible for the production of increased levels of ROS and subsequent activation of the Nrf2 pathway in the HIV-1-infected cells. Activation of the Nrf2 pathway by Tat was further manifested by enhanced transcription of the downstream Nrf2 target genes such as NQO1, HO-1, and aldo-ketoreductase 1C1 (AKR1C1) [63]. Interestingly, the Nrf2 pathway turned out to play a critical role in the inhibition of the LTRdependent transcription of viral genes [63]. These findings suggested a pharmacological modulation of the Nrf2 pathway as a plausible antiviral strategy for the abrogation of the LTR-dependent transcription by HIV [63].

3.3. Hepatitis C Virus (HCV). HCV infection is responsible for the development of chronic hepatitis [69]. Several HCV proteins, including core, NS3, and NS5A, have been ascribed to induction of oxidative stress in human hepatoma cells [36, 37, 70, 71]. Hepatocellular damage from HCV has been linked to $\mathrm{HCV}$-induced oxidative stress. [35]. On the other hand, production of ROS by HCV infection was shown to induce phosphorylation and nuclear translocation of $\mathrm{Nrf} 2$, thereby transactivating its target genes such as NQO1, HO-1, and $\gamma \mathrm{GCSH}$ [48]. Particularly, cellular kinases including JNK, ERK1/2, p38 mitogen-activated protein kinases (MAPKs), phosphatidylinositol 3-kinase/Akt (PI3K-Akt), protein kinase $\mathrm{C}$ (PKC), and casein kinase 2 have been implicated in phosphorylation and activation of Nrf2 [72-75]. Based on these findings, the activation of the Nrf2 pathway was proposed to be one of the potential mechanisms for the survival of HCV-infected cells [48].

Chronic hepatitis $\mathrm{C}$ was shown to be in a frequent association with steatosis, accumulation of lipid droplet [76]. In order to study the HCV-induced steatosis, Sugiyama et al. successfully established a persistently infected hepatoma cell line and maintained it for more than a year [77]. As expected, a remarkable accumulation of lipid droplets was detected in this cell line [77]. Integrated analysis of metabolomics and expression arrays revealed a constitutive upregulation of the Nrf2 pathway-associated genes including NQO1, GCLC, Maf, glucose 6 phosphate dehydrogenase (G6PD), methylenetetrahydrofolate dehydrogenase 2 (MTHFD2), and asparagine synthetase (ASNS) [77]. In particular, Nrf2 phosphorylation was also found to be increased in the nuclear extract of these cells [77]. Knockdown of Nrf2 significantly suppressed steatosis and $\mathrm{HCV}$ infection [77]. These findings imply a negative modulation of the Nrf2 pathway as a promising strategy to dampen the $\mathrm{HCV}$-induced steatosis.

Nrf2-dependent metabolic reprogramming and its positive implication in the $\mathrm{HCV}$ disease progression were examined by Saito et al. [78]. In this study, a phosphomimetic version of p62, which is a negative modulator of KEAP1, was designed and expressed [78]. Interestingly, this phosphomimetic p62 was found to activate the Nrf2 pathway [78]. This, in turn, facilitated the malignant progression of hepatocellular carcinoma (HCC) by $\mathrm{HCV}$ [78]. Downstream Nrf2 target genes such as phosphogluconate dehydrogenase (PGD), GCLC, NQO1, and UDPglucose dehydrogenase (UGDH) were all found to be upregulated at the transcriptional level by the phosphomimetic p62 [78]. Consequently, this p62-dependent Nrf2 activation gave rise to a robust GSH production, resulting in tolerance to anticancer drugs and enhanced proliferative capacity in infected hepatoma cells [78]. Based on these findings, a specific inhibitor for KEAP1 and phospho-p62 interaction, K67, was identified by a high-throughput screening [78]. This Nrf2 inhibitor was able to suppress tumor growth and tolerance to anticancer agents, further confirming the molecular targeting of p62 as a potential chemotherapeutic strategy to combat HCC by HCV [78].

As previously noted, HCV associated with oxidative stress leads to the activation of the Nrf2 pathway [72-75]. In contrast to this, Carvajal-Yepes et al. discovered a unique mechanism for active downregulation of the Nrf2 pathway by an HCV infection [49]. According to their study, the viral proteins such as core and NS3 were able to induce mislocalization of small Maf, which is a partner transcription factor for Nrf2, resulting in inhibition of Nrf2-dependent expression of target genes such as NQO1, GCLC, and GPx [49]. Overall proteasomal activity was also downregulated in the infected cells [49]. Therefore, depending on the cellular contexts and levels of oxidative stress, HCV infection seems to exert a differential influence on the Nrf2 pathway [49].

3.4. Influenza Virus. Influenza viruses have been demonstrated to be a causative agent for oxidative stress and respiratory inflammation by a number of studies [41, 79-82]. In line with these observations, an influenza virus was shown to induce apoptosis and cytotoxicity in alveolar epithelial cells, as manifested by an increased expression of caspase 1 , caspase 3, and a proinflammatory cytokine, IL-8 [44]. Therefore, attenuation of oxidative stress and inflammation by a pharmacological measure may be beneficial for lessening an influenza virus-induced lung injury and exacerbation of existing respiratory diseases. Interestingly, this influenza virusinduced oxidative stress, in turn, was able to activate the Nrf2 pathway through the facilitation of the nuclear translocation of Nrf2 and subsequent expression of the Nrf2 target genes like HO-1 in the human alveolar epithelial cells [44]. Consequently, induction of the Nrf2 downstream genes was able to protect the infected cells against virus-induced cellular injury [44]. Similar lung injury induced by lipopolysaccharide (LPS) was also shown to be alleviated by activation of the Nrf2 pathway [83]. However, in contrast to this observation, a proteomic analysis performed by Simon et al. found a negative impact of the influenza virus infection on the Nrf2 pathway [84]. In this report, virus-infected human bronchial adenocarcinoma cells were found to have a lower amount of a phosphorylated form of Nrf2 in their nuclei [84]. Similar to HCV infection, this cellular context-dependent differential modulation of virus-induced antioxidative responses seems to be another recurring theme in the case of the influenza virus. 
3.5. Respiratory Syncytial Virus. Respiratory syncytial virus (RSV) is responsible for viral upper and lower respiratory tract infections in infants and young children [85]. RSV infection is associated with the development of severe lower respiratory illness associated with bronchiolitis and respiratory failure [85]. RSV infection of airway epithelial cells was shown to induce ROS production, which is involved in transcription factor activation and chemokine gene expression for inflammation and innate immune defense [86, 87]. In line with these results, RSV infection was reported to induce a significant increase in lipid peroxidation products as well as a significant decrease in the GSH/GSSG ratio in human alveolar type II-like epithelial cells and small airway epithelial cells [20]. However, in spite of virus-induced oxidative stress, RSV infection was able to abrogate activation of the Nrf2 pathway, resulting in a reduction in the expression levels of Nrf2 target genes including HO-1, SOD1, SOD3, GST, CAT, and GPx [20]. Consequently, the virus-induced cellular oxidative damage was further accelerated [20,88]. Although another group of researchers reported activation of the Nrf2 pathway by RSV infection, as verified by the nuclear translocation of Nrf2 and the increased expression of Nrf2 target genes such as GCLC, UGT1, NQO1, HO-1, GST, and GPx in the normal mice, this Nrf2 activation was very transient and disappeared only one day after RSV infection [19]. In addition, lack of Nrf2-dependent antioxidant expression in mice genetically deficient in Nrf2 was also shown to exacerbate lung inflammation and injury [19]. In line with this, analysis of bronchoalveolar lavage proteins retrieved from RSV-infected mice revealed a global reduction in expression of antioxidant enzymes including SOD1, SOD3, CAT, GST, and GPx through inactivation of the Nrf2 pathway [20, 89]. Collectively, RSV seems to be gifted with a special power for active downregulation of the Nrf2 pathway to facilitate its pathogenesis.

In regard to potential mechanisms for inactivation of the Nrf2 pathway by RSV, dysregulation of posttranslational modification of Nrf2 was suggested [90]. Basically, RSVinduced deacetylation, SUMOylation, and the following proteasomal degradation of $\mathrm{Nrf} 2$ were shown to be responsible for downregulation of transcription of Nrf2-dependent genes such as NQO1, CAT, and SOD1 [90]. In particular, a SUMOspecific E3 ubiquitin ligase, RING finger protein 4 (RNF4), was shown to play a central role in the process of RSVinduced Nrf2 degradation [43]. In support of this mechanism, treatment of the histone deacetylase (HDAC) inhibitor, trichostatin A (TSA), significantly facilitated acetylation and degradation of Nrf2 [90]. In addition, RSV infection gave rise to a significant reduction in binding of the transacetylase, CBP, to the ARE site of the SOD1 gene promoter [90]. Based on these findings, a pharmacological recuperation of the Nrf2 pathway by an Nrf2 activator could be employed to produce ameliorating effects on the RSV-induced pathogenesis.

3.6. Hepatitis B Virus (HBV). HBV is regarded as one of the major etiological factors in the development of HCC [91]. Accumulating evidence has suggested a constitutive activation of the Nrf2 pathway in various human cancers [92-96]. In many tumors, increased expression of $\mathrm{Nrf2}$ target genes was considered beneficial for tumor cells' escape from chemotherapy-induced cytotoxicity through upregulation of antioxidative response [97, 98]. Chronic inflammation and concomitant cellular stress due to permanent overproduction of ROS-inducing viral proteins have been associated with the development of HCC by $\operatorname{HBV}[15,16]$. HBV infection was reported to induce a strong activation of the Nrf2 pathway [99]. More specifically, HBV protein X (HBx) and large $\mathrm{HBV}$ surface protein (LHB) were shown to be responsible for activation of the Nrf2 target genes such as NQO1, GPx, and GCL [99]. This HBV-dependent induction of the Nrf2-regulated genes seems to protect infected cells from oxidative damage [99]. In regard to a potential mechanism for HBx-induced activation of the Nrf2 pathway, ATM kinase, which is a well-known DNA damage sensor, was implicated in this process [100]. In this report, $\mathrm{HBx}$ induced ROS generation increased a phosphorylated form of ATM, resulting in facilitating the Nrf2-dependent transcription of HO-1, NQO1, and G6PD genes $[46,100]$. In this report, $\mathrm{HBx}$ was able to augment the interaction between KEAP1 and p62. Since p62 is a negative regulator of KEAP1, increased association of KEAP1 with p62 by HBx liberates Nrf2 from the KEAP1-Nrf2 complex, leading to the activation of the Nrf2 pathway. Consequently, transcription of Nrf2 target genes including G6PD, NQO1, GST, and Cyp2a5 was increased [46]. Upregulation of another Nrf2 target gene, the insulin receptor, by HBV infection was also described [101]. However, in contrast to a robust induction of Nrf2 by $\mathrm{HBV}$ infection, infection by $\mathrm{HBV}$ genotype $\mathrm{G}$ was shown to inhibit activation of the Nrf2 pathway due to intracellular accumulation of subviral HBsAg particles [52]. Levels of the Nrf2 target genes such as NQO1, AP1, and GPx were also significantly decreased in these $\mathrm{HBV} / \mathrm{G}$ replicating cells [52]. In addition to the influenza virus and RSV, differential modulation of the Nrf2 pathway based on cellular contexts also seems to be applicable in the case of the HBV infection.

3.7. Herpes Virus. ROS production and its associated oxidative tissue damage have been shown to play a causative role in herpes simplex virus- (HSV-) 1-induced neuropathology [102-104]. Subsequent antioxidant gene induction was also observed during experimental herpes encephalitis [105]. Particularly, upregulation of the Nrf2 target genes such as HO-1 and GPx was confirmed in the herpes disease model [105]. In this report, astrocytes were shown to mediate antioxidative stress response upon HSV-1 infection [105]. Another type of herpes virus, human cytomegalovirus (HCMV), also demonstrated activation of the Nrf2 pathway for neutralization of the cytotoxic effects of ROS [106]. In this report, HCMVinfected cells have increased levels of Nrf2-dependent antioxidant and detoxifying enzymes such as SOD, GPx, GCLC, HO-1, and NQO1 [106]. This led to an increase in the glutathione levels in the virus-infected cells [106]. Lee et al. also reported a similar result, which described the protection of host cells from oxidative stress via upregulation of Nrf2 expression by HCMV infection [42]. In this study, expression of the Nrf2 target genes such as HO-1 and GCLC was induced by virus immediate early (IE) proteins irrespective of ROS [42]. This suggests existence of a ROS-independent 
mechanism for activation of the Nrf2 pathway in the case of HCMV infection. Specifically, CK2 kinase was shown to be involved in this $\mathrm{HCMV}$-mediated activation of $\mathrm{Nrf} 2$ [42]. Another type of herpes virus, a Kaposi's sarcomaassociated herpesvirus (KSHV), plays an etiological role in the development of Kaposi's sarcoma and primary effusion B-cell lymphoma $[107,108]$. KSHV has been implicated in the Nrf2 induction upon infection of endothelial cells [45]. In this report, de novo KSHV infection of human dermal microvascular endothelial cells activated the Nrf2 pathway through the ROS-mediated dissociation of KEAP1 from the Nrf2-KEAP1 complex and subsequent Nrf2 phosphorylation and nuclear translocation [45]. This led to an increased expression of the Nrf2 target genes such as NQO1 and HO-1 [45]. In particular, activated Nrf2 was found to be colocalized with the KSHV genome as well as with the latency protein LANA-1, further suggesting a potential role of Nrf2 in the direct regulation of transcription and replication of KSHV genomes [45].

3.8. Dengue Virus. Dengue virus (DENV) is an arthropodborne tropical virus responsible for the development of dengue fever and related diseases [109, 110]. Study of DENV infection suggests the presence of an important interplay between the generation of oxidative stress and the immunopathology of DENV disease. Preferential activation of the Nrf2 pathway by a DENV infection in primary human monocyte-derived dendritic cells was reported by using a genome-wide transcriptome analysis [39]. In this report, the cellular oxidative stress response is required for the DENV-induced innate immune responses [39]. In particular, accumulation of intracellular NOX-derived ROS in infected cells was required for potentiation of the immune response [39]. The Nrf2 target genes, which are stimulated by a DENV infection, include HO-1, NQO1, SOD2, GCLM, and GCLC [39]. Another example of the activation of the Nrf2 pathway by DENV in mononuclear phagocytes was also described [47]. In this study, DENV NS2B3 protein was shown to be involved in ER stress induction and activation of the Nrf2 pathway. The NS2B3-induced activation of the Nrf2 pathway resulted in upregulation of c-type lectin domain family 5 , member A (CLEC5A) and ultimately production of tumor necrosis factor- (TNF-) $\alpha$ [47].

3.9. Marburg Virus. Marburg virus (MARV) is a causative agent for lethal hemorrhagic fever in humans [111]. Two separate research groups demonstrated activation of the Nrf2 pathway by MARV infection through inhibitory effects of the viral protein VP24 on KEAP1 [112, 113]. In their studies, the VP24 binding site was found to be located within the Kelch domain of KEAP1, which happened to overlap with the Nrf2-binding site [112, 113]. Therefore, expression of VP24 induced Nrf2 activation and transcription of the Nrf2-dependent genes such as HO-1, NQO1, and GCLM [112, 113]. Interestingly, VP24 dimerization was shown to play a role in the regulation of VP24KEAP1 interaction since the loss of VP24 dimerization resulted in increased KEAP1 binding and VP24-dependent ARE promoter activity [114]. Therefore, pharmacological inhibition of the Nrf2 pathway may be useful for dampening the MARV-associated pathogenesis.

3.10. Spring Viremia of Carp Virus (SVCV). Spring viremia of carp virus (SVCV) is the etiological agent of spring viremia of carp [115]. SVCV infection was able to upregulate the cellular total antioxidant capacity and Nrf2 expression, leading to an increase in the expression of the Nrf2 target genes such as HO-1 and SOD1 [116, 117]. Elevated production of ROS upon SVCV infection seems to be responsible for activation of the Nrf2 pathway [116, 117].

3.11. West Nile Virus. West Nile virus (WNV) infection plays an etiological role in the development of neuroinvasive disease such as a mosquito-borne encephalitis [118-120]. WNV infection was also shown to activate the Nrf2 pathway, as evidenced by a significant increase in antioxidant gene expressions such as GCLC, SOD, and GPx [121]. In this report, increased GSH levels via activation of the Nrf2 pathway inhibited arsenite-induced stress granule formation in WNV-infected BHK cells. Based on these observations, authors suggest that WNV-induced activation of the Nrf2 pathway protects infected cells against mitochondrial damage induced by arsenite-induced ROS [121].

3.12. Red-Spotted Grouper Nervous Necrosis Virus. Red-spotted grouper nervous necrosis virus (RGNNV), a pathogenic fish virus, induced oxidative stress, apoptosis, and postapoptotic necrosis in a grouper liver cell line [122]. RGNNV infection was shown to be capable of ROS production and subsequent upregulation of antioxidant enzymes such as $\mathrm{Cu} / \mathrm{Zn}$ SOD and catalase in GF-1 cells [122].

\section{Therapeutic Modulation of a Viral Pathogenesis via an Nrf2-Dependent Antioxidative Pathway}

Some viruses induce oxidative stress on purpose for a successful completion of a virus life cycle. However, uncontrolled virus-induced oxidative stress exacerbates the condition of the infected cells. Therefore, upregulation of the cytoprotective and detoxifying protein seems to be beneficial not only for disruption of the ROS-dependent steps of the viral life cycle but also for the amelioration of the exacerbated conditions of the infected host cells. In this regard, numerous pharmacological agents were shown to activate the Nrf2 pathway and lessen the burden of virus-induced oxidative stress [10, $11,14,22,35-38,40,123]$. In addition, a number of Nrf2 overexpression and knockdown studies also demonstrated the direct involvement of the Nrf2 pathway in the pathogenesis of some viruses [124-127]. Here, I would like to introduce studies describing the effects of Nrf2 modulators and genetic manipulation of $\mathrm{Nrf} 2$ on virus replication and virally induced pathogenesis. Detailed effects of pharmacological and genetic alterations of the Nrf2 pathway on Nrf2 protein, Nrf2 target genes, ROS level, viral pathogenesis, and virus replication are summarized in Table 2.

4.1. MoMuLV ts1. $\alpha$-Luminol (monosodium 5-amino-2-3dihydro-1-4-phthalazine dione) is an anti-inflammatory 


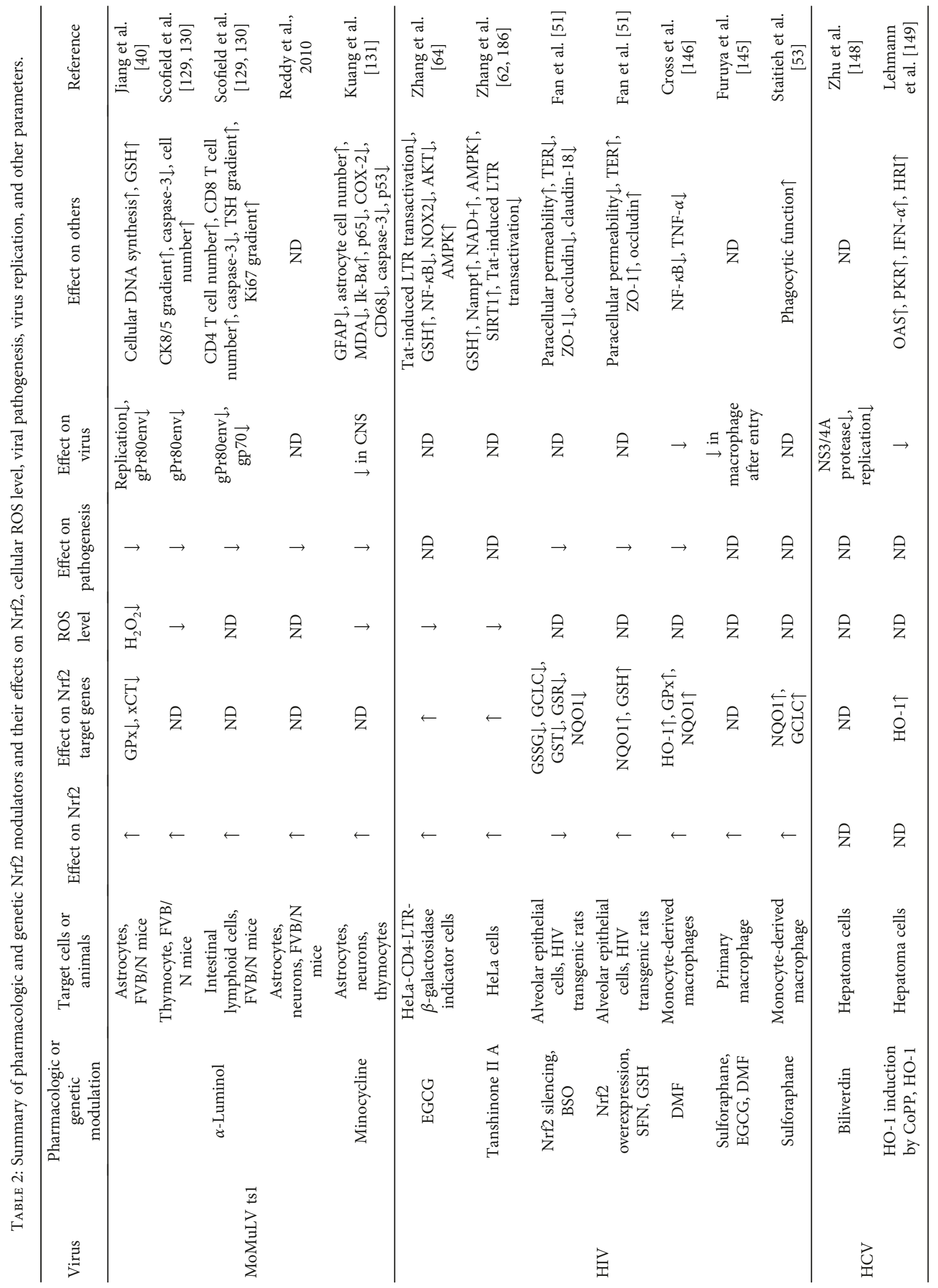




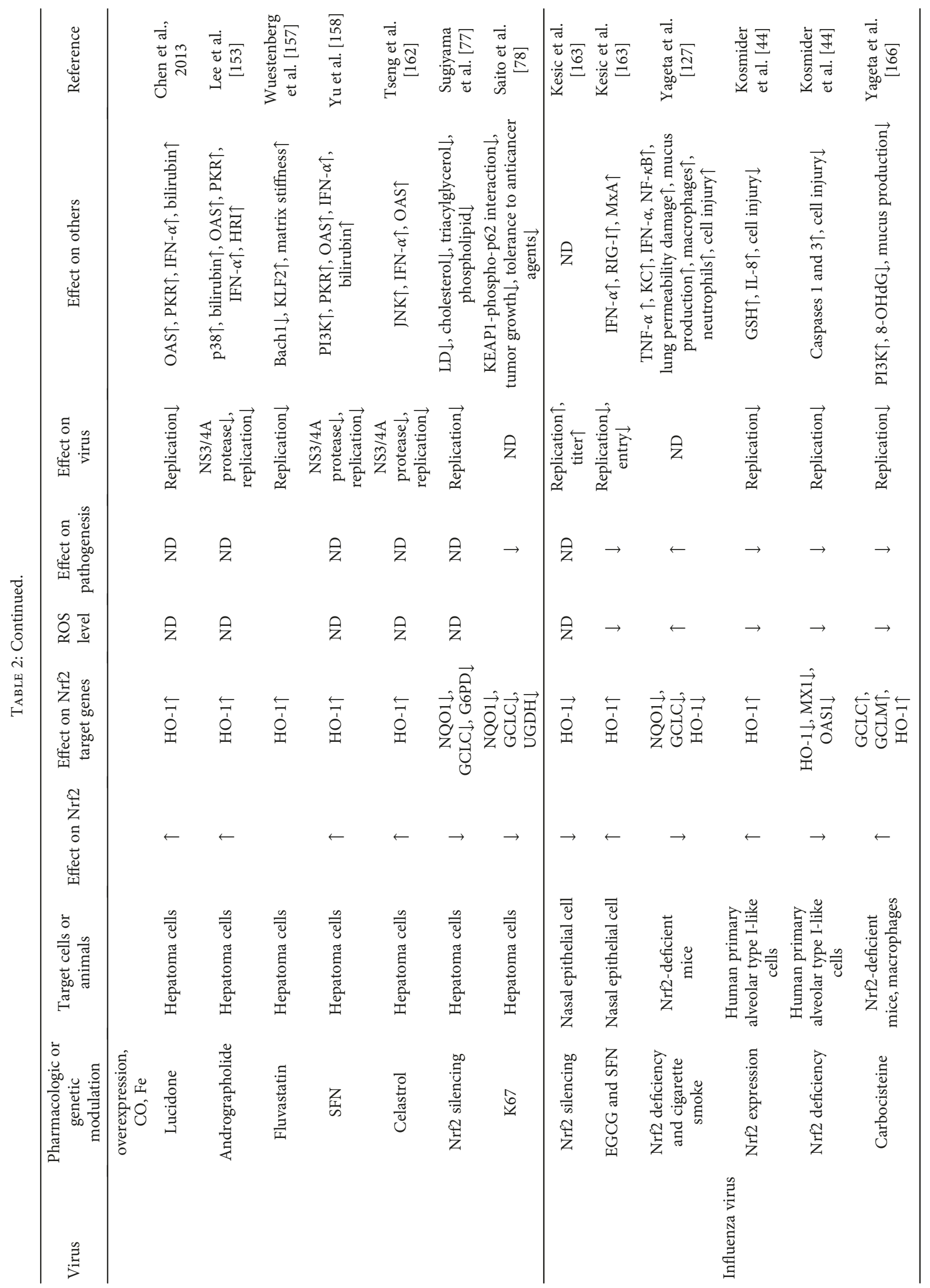




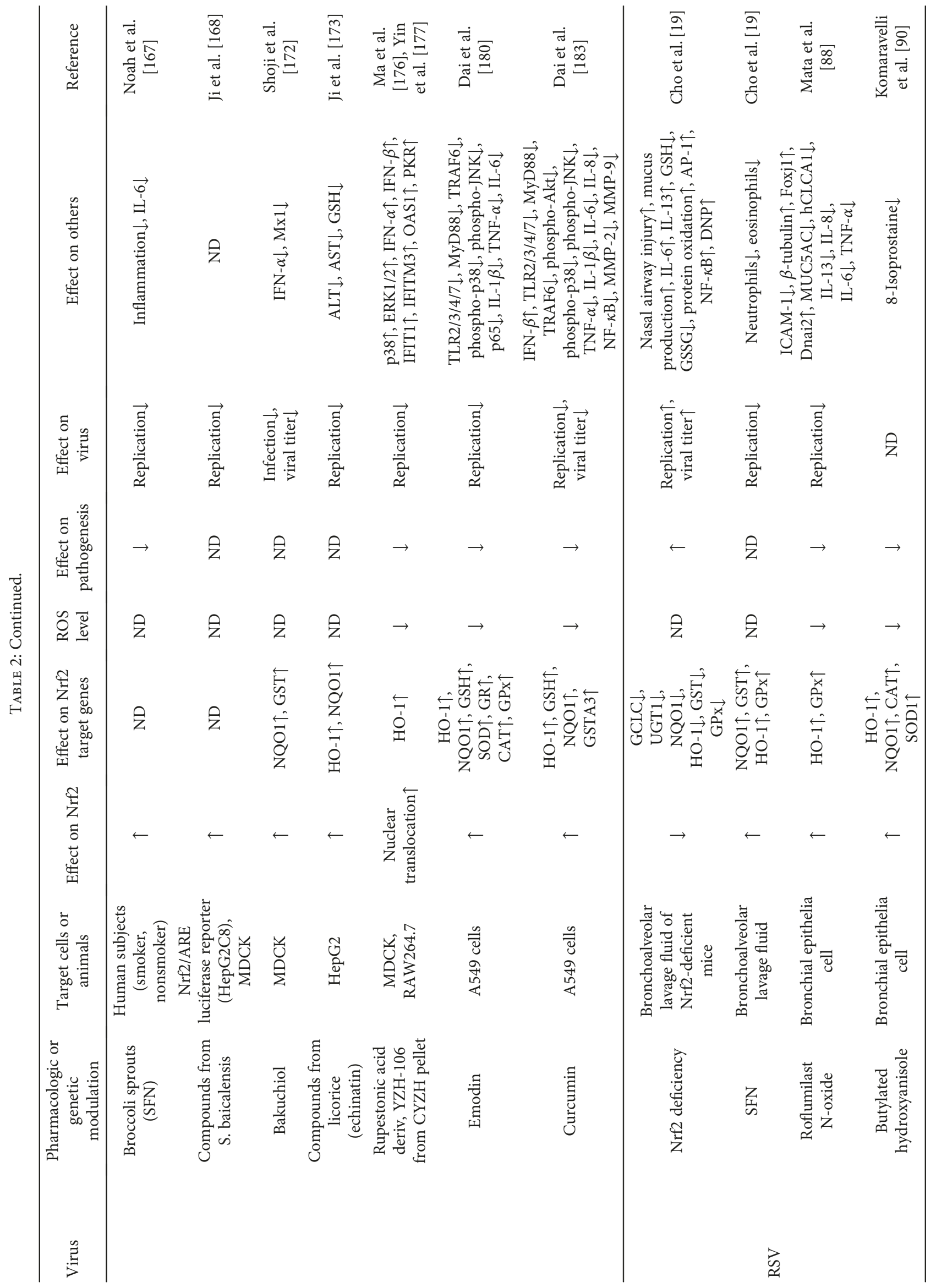




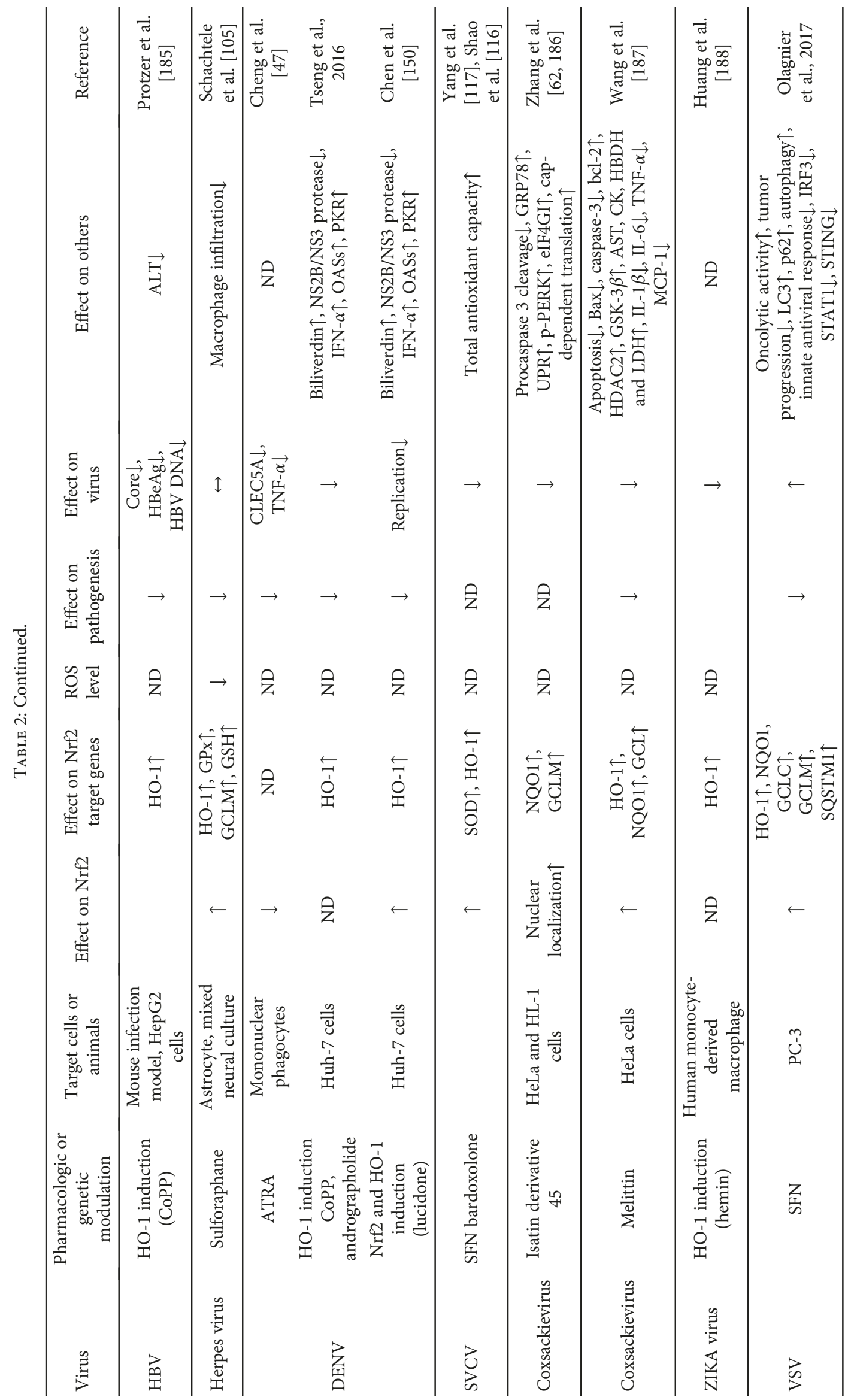




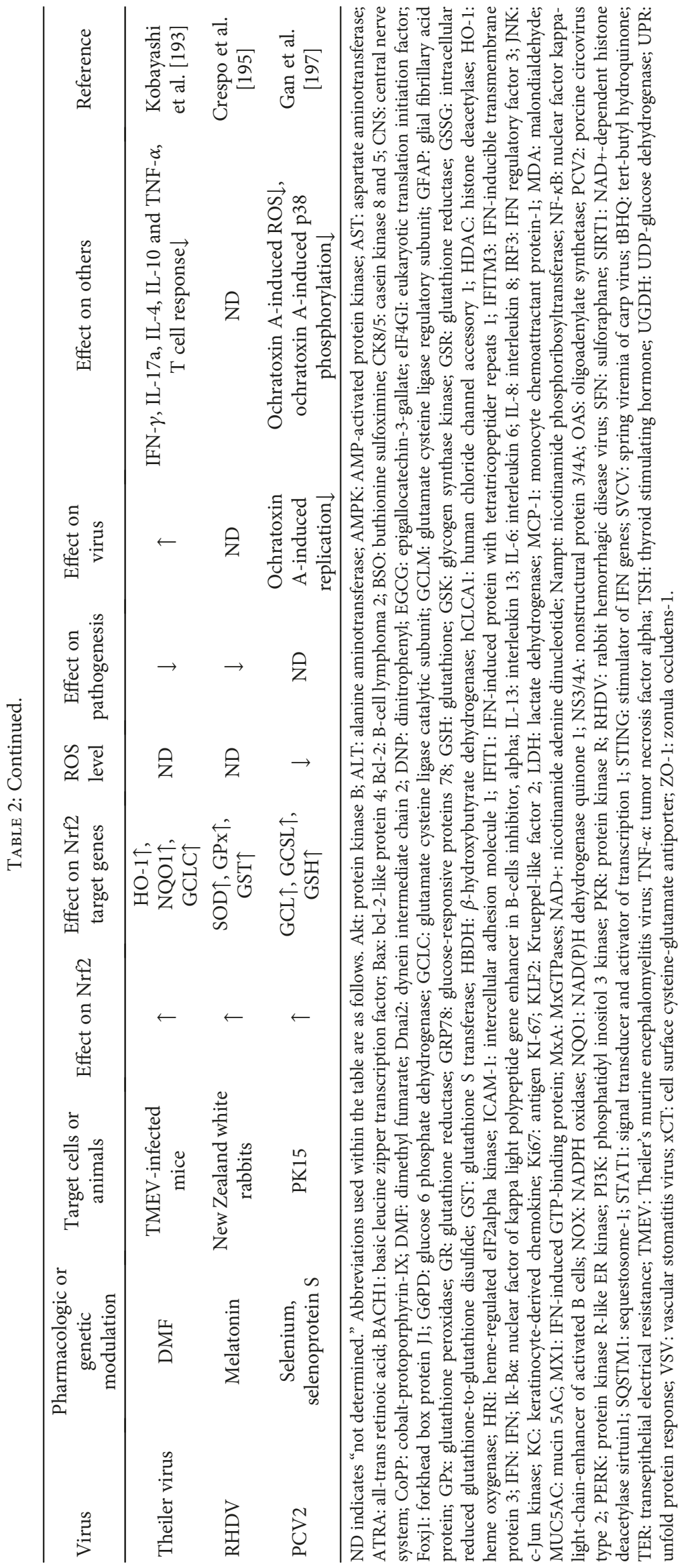


drug extensively studied by Russian scientists [128]. Jiang et al. demonstrated that treatment with $\alpha$-luminol was able to suppress oxidative stress induced by MoMuLV ts 1 infection [40]. In addition, $\alpha$-luminol abrogated upregulation of Nrf2 in MoMuLV ts1-infected astrocytes, resulting in restoration of increased GPx and cell surface cysteine-glutamate antiporter (xCT) to a normal level [40]. This led to the reduction of $\mathrm{H}_{2} \mathrm{O}_{2}$ and recuperation of cellular DNA synthesis and the GSH level [40]. In in vivo animal study, $\alpha$-luminol was able to suppress the neurodegeneration in MoMuLV ts1infected mice [40]. Particularly, early $\alpha$-luminol treatment even blocked ts 1 replication and expression of the gPr80env protein in the CNS of MoMuLV ts1-infected mice [40]. Based on these observations, they concluded that $\alpha$-luminol suppresses virus replication and virus-induced cytopathology in the CNS by reducing oxidant stress [40]. In line with these evidence, Scofield et al. also reported a positive role of $\alpha$ luminol in the preservation of epithelial cell cytoarchitecture and promotion of thymocyte survival in MoMuLV ts1infected mice [129]. In particular, gPr80env accumulation was completely prevented in mice treated with $\alpha$-luminol [129]. Similar protective effects of $\alpha$-luminol were also observed in the intestines of MoMuLV ts1-infected mice [130]. Treatment of $\alpha$-luminol was able to preserve cryptvillus epithelial organization and allows survival of intestinal $\mathrm{T}$ cells in the MoMuLV ts1-infected mice [130]. Interestingly, intestinal epithelial cells were found to contain higher levels of the Nrf2 protein after $\alpha$-luminol treatment [130]. Suppression of ROS by treatment of $\alpha$-luminol seems to be beneficial in retarding the pathogenesis of MoMuLV ts1 infection through Nrf2-dependent neutralization of virus-induced oxidative stress [130]. On the other hand, Kuang et al. also demonstrated a similar neuroprotective effect of minocycline through direct radical scavenging and upregulation of Nrf2mediated antioxidant defenses [131]. In this report, decreased Nrf2 levels by MoMuLV ts1 were enhanced by treatment of minocycline [131]. However, in spite of treatment of minocycline, a viral titer remained unaltered, suggesting that a virus replication is not the primary target of minocycline [131].

4.2. HIV. Epigallocatechin-3-O-gallate (EGCG), the predominant catechin from tea, is known to exert a variety of biological activities [132-135]. In particular, antiviral activities of EGCG were shown in the context of HIV-1 infection [136, 137]. In regard to possible antiviral mechanisms by EGCG, Zhang et al. reported modulation of Tat-induced LTR transactivation by EGCG [64]. In this paper, EGCG was able to induce a significant improvement on the cellular alterations associated with Tat-induced oxidative stress. These beneficial effects of EGCG seem to be mediated by increasing nuclear levels of Nrf2 and decreasing levels of NF- $\kappa \mathrm{B}$ [64]. Based on these results, the $\mathrm{Nrf} 2$ signaling pathway was suggested as the primary target for prevention of Tat-induced HIV-1 transactivation. A similar antagonizing effect of another natural compound, called tanshinone II A, on Tat-induced HIV1 transactivation was also reported [62]. Tanshinone II A is a lipid-soluble monomer derivative of phenanthrenequinone extracted from the root of Salvia miltiorrhiza (Danshen)
$[138,139]$. In this study, tanshinone II A was shown to reverse Tat-induced ROS production and downregulation of GSH levels through upregulation of Nrf2 expression [62]. In particular, this inhibition of Tat-induced HIV-1 LTR transactivation by tanshinone II A was dependent on the AMP-activated protein kinase- (AMPK-) nicotinamide phosphoribosyltransferase (Nampt) pathway [62]. Based on this observation, the authors proposed the AMPK/Nampt/ SIRT1 pathway as a promising anti-HIV target [62].

As previously noted, HIV-1 transgene expression in rats significantly dampens alveolar macrophage phagocytic capacity [67]. In particular, HIV-1-related viral proteins such as gp120 and Tat seem to be directly involved in this oxidative stress-cytotoxicity through glutathione depletion in target cells [38]. Fan et al. demonstrated downregulation of Nrf2 expression via RNA interference inhibited Nrf2dependent antioxidant gene expressions such as GSSG, GCLC, GST, glutathione reductase (GSR), and NQO1. These changes induced by lack of Nrf2 were eventually translated into decreased intracellular glutathione levels, increased epithelial barrier permeability, and decreased transepithelial electrical resistance (TER) in alveolar epithelial cells of HIV transgenic rats [51]. In particular, alteration of tight junction protein expression and localization was worsened by the interference of Nrf2 expression [51]. In contrast, Nrf2 overexpression improved epithelial barrier function as well as tight junction expression and localization in alveolar epithelial cells of HIV transgenic rats [51]. These data suggest the importance of the integrity of the Nrf2 pathway in protecting cells against oxidative stress induced by HIV-1 infection.

Sulforaphane (SFN) is an isothiocyanate abundant in cruciferous vegetables. It is famous for its cytoprotective effects shown by numerous in vivo and in vitro studies $[140,141]$. SFN has been found to be a powerful activator of the Nrf2 pathway [142-144]. SFN increased Nrf2regulated cellular antioxidant response such as induction of NQO1 and glutathione and protected alveolar epithelial cells against HIV-1-induced barrier dysfunction [51]. SFN was also shown to inhibit HIV infection of macrophage [145]. In this study, SFN suppressed HIV infection through blockage of HIV envelope-mediated viral entry [145]. In addition, SFN was able to restore the decreased phagocytic function of the HIV-infected alveolar macrophages by stimulating Nrf2dependent antioxidative functions such as expression of NQO1 and GCLC [53]. Cross et al. also showed another Nrf2 activator, dimethyl fumarate (DMF), was able to suppress HIV replication and macrophage-mediated neurotoxicity [146]. In this report, DMF treatment was able to upregulate transcription of Nrf2 target genes such as HO-1, GPx, and NQO1. It was also able to inhibit HIV replication and HIV-mediated neurotoxicity in human monocytederived macrophages [146]. Particularly, induction of HO-1 by DMF was demonstrated to reduce neurotoxin production from human monocyte-derived macrophages [146].

4.3. HCV. HO-1 is one of the best-characterized Nrf2 target genes, readily inducible in response to a variety of oxidative stress and cytotoxic insult. HO-1 catalyzes the oxidation of heme to biliverdin (BV), carbon monoxide, and iron [147]. 
Zhu et al. demonstrated that a genetic or pharmacologic induction of $\mathrm{HO}-1$ led to inhibition of $\mathrm{HCV}$ replication through blockage of a viral NS3/4A protease [148]. BV, an end product of heme oxidation by HO-1, was also shown to possess an anti-HCV activity [149]. Since free BV is rapidly reduced to bilirubin by the enzyme biliverdin reductase (BVR) in the hepatocyte, the antiviral activity of BV was significantly enhanced by BVR knockdown [148]. In addition to this mechanism, BV was also shown to interfere with HCV replication by activation of antiviral IFN response including increased expression of oligoadenylate synthetase (OAS), protein kinase $\mathrm{R}$ (PKR), interferon- (IFN-) $\alpha$, and hemeregulated eIF2alpha kinase (HRI) [149]. Lucidone, a natural compound, isolated from the fruits of Lindera erythrocarpa Makino, was also found to suppress $\mathrm{HCV}$ replication by Nrf2-mediated HO-1 induction [150]. In this report, lucidone augmented antiviral IFN response by upregulation of OAS1, 2, and 3 and PKR. It suppressed HCV NS3/4A protease activity through biliverdin production as well [150]. Andrographolide, the most abundant diterpene lactone in the leaves and stems of $A$. paniculata $[151,152]$, was demonstrated to work against $\mathrm{HCV}$ replication through upregulation of HO-1 via the Nrf2 pathway [153]. In this study, andrographolide enhanced the production of biliverdin, resulting in activation of antiviral IFN response and suppression of HCV NS3/4A protease activity [153]. Particularly, p38 MAPK was shown to be involved in this Nrf2mediated HO-1 increase by andrographolide [153]. In an attempt to stimulate HO-1 activity, cholesterol-lowering drugs, statins, were used to induce expression of the HO-1 in a variety of cells [154-156]. Among them, fluvastatin was shown to inhibit HCV replication by induction of HO-1 [157]. On the other hand, Yu et al. showed suppression of $\mathrm{HCV}$ replication by SFN through upregulation of $\mathrm{HO}-1$ expression. In this study, SFN was able to stimulate BV production to activate antiviral IFN response and suppress HCV protease activity [158]. In regard to a more detailed mechanism, SFN was found to stimulate PI3K phosphorylation, which contributed to Nrf2/HO-1-mediated inhibition of HCV replication [158]. Celastrol, a quinone methide triterpene isolated from Tripterygium wilfordii [159-161], was also shown to inhibit HCV replication by upregulating HO1 via the Nrf2 pathway in human hepatoma cells [162].

Although previous data all pointed out inhibitory effects of Nrf2-activating pharmacological agents on HCV replication through different mechanisms, following two studies demonstrated differential effects of the Nrf2 pathway on $\mathrm{HCV}$ replication. Sugiyama et al. showed knockdown of Nrf2 neutralized the increasing effect of chronic HCV infection on levels of lipid droplets, resulting in inhibition of $\mathrm{HCV}$ replication [77]. Saito et al. demonstrated that K67, a previously introduced $\mathrm{Nrf} 2$ inhibitor, was able to reduce the expression of Nrf2 target genes such as NQO1, GCLC, and UGDH. However, this drug failed to produce any direct effects on HCV replication [78].

4.4. Influenza Virus. Kesic et al. showed suppression of Nrf2 gene expression enhanced influenza virus replication; meanwhile, pharmacological induction of Nrf2 via supplementation such as SFN and EGCG suppressed viral replication [163]. This data indicates a causal relationship between the EGCG-induced activation of Nrf2 and the ability to protect against viral replication [163]. In regard to the antiviral mechanism of action, a viral entry seems to be the plausible step, which is negatively targeted by activation of the Nrf2 pathway [163]. In addition, antioxidant supplementation with EGCG significantly increased the mRNA expression levels of the innate immunity-related genes such as IFN- $\beta$, RIG-I, and MxA [163]. Nrf2 knockout mice displayed elevated oxidative stress and inflammatory gene expression by an influenza virus infection, further emphasizing the importance of the Nrf2 pathway in protection against influenza virus infection [127]. In addition, Nrf2 overexpression stimulated expression of HO-1 and protected alveolar cells against injury induced by the influenza virus and decreased influenza infection in alveolar cells [44]. In line with the protective role of the Nrf2 pathway in the pathogenesis of an influenza virus infection, Nrf2 knockdown downregulated Nrf2 target genes such as HO-1, MX1, and OAS1 and sensitized alveolar cells to oxidative injury induced by an influenza virus [44]. Carbocisteine, also known as S-carboxymethyl cysteine (S-CMC) or (2R)-2- amino-3-carboxymethyl sulfanyl propanoic acid, is a mucoregulatory drug with an antiinflammatory property $[164,165]$. Carbocisteine was able to activate $\mathrm{Nrf} 2$ and enhance Nrf2-mediated antioxidant gene expressions such as GCLC, GCLM, and HO-1 in macrophages [166]. Carbocisteine was also able to decrease the expression of virus nucleoprotein, an indicator of viral replication [166]. In the clinical evaluation of the Nrf2 activator for pulmonary diseases, a short-term ingestion of broccoli sprout homogenates, which are enriched in SFN, was found to significantly reduce an influenza virus-induced inflammation as well as virus quantity in smokers [167]. Compounds isolated from $S$. baicalensis were reported to display an anti-influenza activity through Nrf2 activation [168]. Bakuchiol is a naturally occurring phenolic isoprenoid isolated from the seeds of Psoralea corylifolia L. [169-171]. Shoji et al. reported that bakuchiol and a series of compounds from licorice induced Nrf2 activation and upregulated NQO1 and glutathione S-transferase (GSTA3) mRNA levels, resulting in reduced expression of influenza A virus $\mathrm{H} 1 \mathrm{~N} 1 \mathrm{mRNAs}$ and proteins $[172,173]$. Rupestonic acid, which is extracted from Artemisia rupestris L., is a sesquiterpene with inhibitory activities against influenza viruses [174, 175]. A rupestonic acid derivative was shown to inhibit influenza replication by upregulating HO-1 expression through promoting Nrf2 nuclear translocation [176, 177]. In particular, p38 MAPK and ERK1/2 pathways seem to be implicated in this upregulation of HO-1 by a rupestonic acid $[176,177]$. In addition, HO-1 induction by this compound augmented antiviral IFN response without HO-1 enzymatic activity [176, 177]. Emodin (1,3,8-trihydroxy-6-methylanthraquinone) is a natural anthraquinone compound from several traditional Chinese medicinal plants $[178,179]$. Emodin was also found to have inhibitory effects on influenza virus replication through an enhanced Nrf2 signal, resulting in the upregulation of Nrf2 target genes such as HO-1, NQO1, GSH, SOD, GR, CAT, and GPx as well as reduction of virus-induced 
oxidative stress [180]. Curcumin is a major active compound of turmeric and is commonly used as a coloring agent and spice in foods [181, 182]. Curcumin was shown to inhibit the replication of the influenza virus and virus-induced oxidative stress in vitro [183]. This inhibitory effects of curcumin on the influenza virus seem to be mediated via the enhanced Nrf2 signal and increased IFN- $\beta$ production via the HO-1 pathway after influenza virus infection [183].

4.5. RSV. RSV infection is associated with a severe lower respiratory illness characterized by bronchiolitis and respiratory failure. It is the leading cause of infant hospitalization [85]. Loss of Nrf2-dependent antioxidant expression in Nrf2 knockout mice has exacerbated lung inflammation and injury [124-126, 184]. Cho et al. showed the antiviral activity of Nrf2 in a murine model of RSV infection [19]. In this report, RSV-infected Nrf2 knockout mice displayed delayed viral clearance, potentiated viral replication, and enhanced body weight loss with reduced expression of Nrf2 target genes such as GCLC, NQO1, HO-1, GST, and GPx [19]. In addition, bronchoalveolar injury and inflammation were more pronounced in these mice [19]. Overall, exacerbation of lung histopathologic phenotypes was observed in these mice. On the contrary, pretreatment of SFN, an Nrf2 activator, suppressed RSV infection and lung inflammation in normal mice but not in Nrf2 knockout mice [19]. These data suggested a key role for the Nrf2 pathway in host defense against RSV [19]. Mata et al. showed the antiviral activity of roflumilast, a phosphodiesterase 4 inhibitor, against RSV infection [88]. In this study, roflumilast alleviated viral burden following RSV infection, reduced RSV-induced intercellular adhesion molecule- (ICAM-) 1 expression, and restored cilia motility in well-differentiated human bronchial epithelial cells [88]. In addition, roflumilast reversed the reduction of Nrf2, HO-1, and GPx mRNA levels [88]. Roflumilast inhibited RSV infection and mitigated the cytopathological changes associated with RSV infection [88]. Butylated hydroxyanisole (BHA) and its metabolite tert-butyl hydroquinone (tBHQ) have been shown to increase HO-1, NQO1, and Nrf2 protein expressions, with significant amelioration of RSV-induced oxidative stress in both primary and cultured cells [90].

4.6. HBV. Protzer et al. showed the antiviral activity of HO-1 in HBV infection [185]. In this paper, HO-1 was either induced by cobalt-protoporphyrin-IX or overexpressed by adenoviral gene transfer [185]. This HO-1 induction protected mice from HBV-induced liver injury and prevented HBV replication [185]. In addition, increased inflammation and liver cell injury in the model of acute hepatitis B were also ameliorated by HO-1 induction [185]. Based on these results, they suggested the induction of $\mathrm{HO}-1$ as a novel therapeutic option for control of inflammation induced by HBV infection [185].

4.7. Herpes Virus. Schachtele et al. reported negative modulation of experimental herpes encephalitis-associated neurotoxicity through SFN treatment [105]. In this study, SFN protected mixed neural cultures from HSV-stimulated microglial toxicity through induction of Nrf2 target genes such as HO-1, GPx, GCLM, and GSH [105]. In addition, systemic SFN injections reduced brain inflammation and ROS production in vivo [105].

4.8. DENV. DENV infection was shown to activate the Nrf2 pathway in mononuclear phagocytic cells [47]. Treating cells with all-trans retinoic acid (ATRA), a potent inhibitor of Nrf2, significantly decreased the DENV-induced Nrf2 activity [47]. In addition, ATRA inhibited c-type lectin domain family 5, member A (CLEC5A) and tumor necrosis factor(TNF-) $\alpha$ expressions. This led to an increase in the survival rate in suckling mice during DENV infection [47]. HO-1 induction by CoPP, andrographolide, and lucidone all suppressed DENV replication, induced $\mathrm{HO}-1$ expression, and delayed DENV-induced lethality in the suckling mouse model through upregulation of biliverdin, IFN- $\alpha$, OASs, and PKR and downregulation of NS2B/NS3 protease [150, 162]. They also significantly increased the IFN-mediated antiviral response in vitro and in vivo [150, 162].

4.9. SVCV. Shao et al. showed pharmacological activation of Nrf2 with SFN and bardoxolone enhanced the cellular total antioxidative capacity by upregulation of SOD1 and HO-1 and dampened SVCV replication [116]. Knocking down the expression of Nrf2 produced the opposite effects [116].

4.10. Coxsackievirus. Zhang et al. found that an isatin derivative was able to inhibit coxsackievirus replication through the Nrf2-dependent upregulation of NQO1 and GCLM [186]. Melittin is a major polypeptide in honey bee venom that has been traditionally used against inflammation. Wang et al. showed that melittin was able to ameliorate coxsackievirus-induced myocarditis via activation of the Nrf2 pathway, resulting in an increased expression of HO-1, NQO1, and GCL [187].

4.11. Zika Virus. Huang et al. showed that hemin is able to induce HO-1 expression via the Nrf2 pathway and this leads to inhibition of Zika virus replication [188]. This inverse correlation between hemin-induced HO-1 levels and ZIKV replication could be utilized to stimulate an innate cellular response against Zika virus infection.

4.12. VSV. Vesicular stomatitis virus (VSV) is a prototypical oncolytic virus that has demonstrated potent oncolytic activity in preclinical models and is being evaluated in clinical trials [189-191]. SFN enhanced VSV replication and oncolysis in PC-3 cells [39]. SFN-VSV combination therapy delayed tumor progression and improved survival in xenograft animal experiments [39]. SFN treatment seemed to dampen the innate antiviral response to assist VSV replication [39].

4.13. Theiler Virus. Intracerebral injection of Theiler's murine encephalomyelitis virus (TMEV) into susceptible strains of mice causes a chronic demyelinating disease [192]. Kobayashi et al. showed that DMF suppressed TMEV-induced demyelinating disease by activating the Nrf2 pathway, resulting in upregulation of HO-1, NQO1, and GCLC [193]. 
4.14. RHDV. Rabbit hemorrhagic disease virus (RHDV) is used as an experimental model to study fulminant hepatic failure [194]. Melatonin was shown to activate the Nrf2 pathway with the increased expression of SOD, GPx, and GST. This activation of the Nrf2 pathway by melatonin prevented a fulminant hepatic failure induced by RHDV infection [195].

4.15. Porcine Circovirus Type 2. Porcine circovirus type 2 (PCV2), a single-stranded DNA virus, is the primary causative agent of several syndromes collectively known as porcine circovirus disease [196]. Gan et al. showed that overexpression of pig selenoprotein S blocked the ochratoxin-induced promotion of PCV2 replication by inhibiting oxidative stress and p38 phosphorylation in PK15 cells [197].

\section{Concluding Remarks}

In this paper, the roles of virus-induced oxidative stress in the viral life cycle and the pathogenesis of viral diseases were reviewed. Particularly, the cellular management of this virus-induced oxidative stress by cellular utilization of the $\mathrm{Nrf} 2$ pathway and its implications in the viral replication and the progression of the viral diseases were explained. In addition, examples of positive and negative regulations of the Nrf2 pathway by a number of pathogenic viruses were described. Finally, various methods of pharmacological and genetic modulations of the Nrf2 pathway as a potential therapeutic option were listed. Considering the significant impact of the Nrf2 pathway on the pathophysiology of both host cell and virus, Nrf2 modulators may be able to serve as a promising supplement for viral diseases by therapeutic modulation of virus-induced oxidative stress in the near future.

\section{Conflicts of Interest}

The author declares that there are no competing interests regarding the publication of this paper.

\section{Acknowledgments}

This work was supported by the National Research Foundation of Korea (NRF) grant funded by the Korea government (MSIT) (No. 2012M3A9C1053532).

\section{References}

[1] M. Hayyan, M. A. Hashim, and I. M. AlNashef, "Superoxide ion: generation and chemical implications," Chemical Reviews, vol. 116, no. 5, pp. 3029-3085, 2016.

[2] M. Strengert, R. Jennings, S. Davanture, P. Hayes, G. Gabriel, and U. G. Knaus, "Mucosal reactive oxygen species are required for antiviral response: role of Duox in influenza a virus infection," Antioxidants \& Redox Signaling, vol. 20, no. 17, pp. 2695-2709, 2014.

[3] A. Soucy-Faulkner, E. Mukawera, K. Fink et al., "Requirement of NOX2 and reactive oxygen species for efficient RIG-I-mediated antiviral response through regulation of MAVS expression," PLoS Pathogens, vol. 6, no. 6, article e1000930, 2010.
[4] A. Narayanan, M. Amaya, K. Voss et al., "Reactive oxygen species activate $\mathrm{NF} \kappa \mathrm{B}$ (p65) and $\mathrm{p} 53$ and induce apoptosis in RVFV infected liver cells," Virology, vol. 449, pp. 270 286, 2014

[5] H. J. Kim, C. H. Kim, J. H. Ryu et al., "Reactive oxygen species induce antiviral innate immune response through IFN- $\lambda$ regulation in human nasal epithelial cells," American Journal of Respiratory Cell and Molecular Biology, vol. 49, no. 5, pp. 855-865, 2013.

[6] C. C. Winterbourn and M. B. Hampton, "Thiol chemistry and specificity in redox signaling," Free Radical Biology and Medicine, vol. 45, no. 5, pp. 549-561, 2008.

[7] R. M. Day and Y. J. Suzuki, "Cell proliferation, reactive oxygen and cellular glutathione," Dose-Response, vol. 3, no. 3, pp. 425-442, 2006.

[8] P. V. B. Reddy, N. Gandhi, T. Samikkannu et al., "HIV-1 gp 120 induces antioxidant response element-mediated expression in primary astrocytes: role in HIV associated neurocognitive disorder," Neurochemistry International, vol. 61, no. 5, pp. 807-814, 2012.

[9] P. V. B. Reddy, M. Agudelo, V. S. R. Atluri, and M. P. Nair, "Inhibition of nuclear factor erythroid 2-related factor 2 exacerbates HIV-1 gp120-induced oxidative and inflammatory response: role in HIV associated neurocognitive disorder," Neurochemical Research, vol. 37, no. 8, pp. 1697-1706, 2012.

[10] U. Paracha, K. Fatima, M. Alqahtani et al., "Oxidative stress and hepatitis C virus," Virology Journal, vol. 10, no. 1, p. 251, 2013.

[11] Y. H. Lee, C. L. Lai, S. H. Hsieh, C. C. Shieh, L. M. Huang, and B. A. Wu-Hsieh, "Influenza A virus induction of oxidative stress and MMP-9 is associated with severe lung pathology in a mouse model," Virus Research, vol. 178, no. 2, pp. 411422, 2013.

[12] M. Kalinowska, D. A. Bazdar, M. M. Lederman, N. Funderburg, and S. F. Sieg, "Decreased IL-7 responsiveness is related to oxidative stress in HIV disease," PLoS One, vol. 8, no. 3, article e58764, 2013.

[13] M. Isaguliants, O. Smirnova, A. V. Ivanov et al., "Oxidative stress induced by HIV-1 reverse transcriptase modulates the enzyme's performance in gene immunization," Human Vaccines \& Immunotherapeutics, vol. 9, no. 10, pp. 2111-2119, 2013.

[14] B. O. Ibeh and I. K. Emeka-Nwabunnia, "Increased oxidative stress condition found in different stages of HIV disease in patients undergoing antiretroviral therapy in Umuahia (Nigeria)," Immunopharmacology and Immunotoxicology, vol. 34, no. 6, pp. 1060-1066, 2012.

[15] T. M. Hagen, S. Huang, J. Curnutte et al., "Extensive oxidative DNA damage in hepatocytes of transgenic mice with chronic active hepatitis destined to develop hepatocellular carcinoma," Proceedings of the National Academy of Sciences, vol. 91, no. 26, pp. 12808-12812, 1994.

[16] B. Rehermann and M. Nascimbeni, "Immunology of hepatitis B virus and hepatitis C virus infection," Nature Reviews Immunology, vol. 5, no. 3, pp. 215-229, 2005.

[17] Y. Imai, K. Kuba, G. Greg Neely et al., "Identification of oxidative stress and Toll-like receptor 4 signaling as a key pathway of acute lung injury," Cell, vol. 133, no. 2, pp. 235249, 2008.

[18] R. P. Garofalo, D. Kolli, and A. Casola, "Respiratory syncytial virus infection: mechanisms of redox control and novel 
therapeutic opportunities," Antioxidants \& Redox Signaling, vol. 18, no. 2, pp. 186-217, 2013.

[19] H. Y. Cho, F. Imani, L. Miller-DeGraff et al., "Antiviral activity of Nrf 2 in a murine model of respiratory syncytial virus disease," American Journal of Respiratory and Critical Care Medicine, vol. 179, no. 2, pp. 138-150, 2009.

[20] Y. M. Hosakote, P. D. Jantzi, D. L. Esham et al., "Viral-mediated inhibition of antioxidant enzymes contributes to the pathogenesis of severe respiratory syncytial virus bronchiolitis," American Journal of Respiratory and Critical Care Medicine, vol. 183, no. 11, pp. 1550-1560, 2011.

[21] H. Nakamura, H. Masutani, and J. Yodoi, "Redox imbalance and its control in HIV infection," Antioxidants \& Redox Signaling, vol. 4, no. 3, pp. 455-464, 2002.

[22] W. E. Stehbens, "Oxidative stress in viral hepatitis and AIDS," Experimental and Molecular Pathology, vol. 77, no. 2, pp. 121-132, 2004.

[23] X. Chen, F. Ren, J. Hesketh et al., "Reactive oxygen species regulate the replication of porcine circovirus type 2 via NF- $\kappa$ B pathway," Virology, vol. 426, no. 1, pp. 66-72, 2012.

[24] A. Ruggieri, S. Anticoli, L. Nencioni, R. Sgarbanti, E. Garaci, and A. Palamara, "Interplay between hepatitis $\mathrm{C}$ virus and redox cell signaling," International Journal of Molecular Sciences, vol. 14, no. 3, pp. 4705-4721, 2013.

[25] P. Moi, K. Chan, I. Asunis, A. Cao, and Y. W. Kan, "Isolation of NF-E2-related factor 2 (Nrf 2), a NF-E2-like basic leucine zipper transcriptional activator that binds to the tandem NF-E2/AP1 repeat of the beta-globin locus control region," Proceedings of the National Academy of Sciences, vol. 91, no. 21, pp. 9926-9930, 1994.

[26] J. Kim and Y.-S. Keum, "NRF2, a key regulator of antioxidants with two faces towards cancer," Oxidative Medicine and Cellular Longevity, vol. 2016, Article ID 2746457, 7 pages, 2016.

[27] M. Kobayashi, L. Li, N. Iwamoto et al., "The antioxidant defense system Keap1-Nrf2 comprises a multiple sensing mechanism for responding to a wide range of chemical compounds," Molecular and Cellular Biology, vol. 29, no. 2, pp. 493-502, 2008.

[28] K. Itoh, N. Wakabayashi, Y. Katoh et al., "Keap 1 represses nuclear activation of antioxidant responsive elements by Nrf 2 through binding to the amino-terminal Neh 2 domain," Genes \& Development, vol. 13, no. 1, pp. 76-86, 1999.

[29] A. Kobayashi, M. I. Kang, H. Okawa et al., "Oxidative stress sensor Keap1 functions as an adaptor for Cul3-based E3 ligase to regulate proteasomal degradation of Nrf2," Molecular and Cellular Biology, vol. 24, no. 16, pp. 7130-7139, 2004.

[30] A. Kobayashi, M. I. Kang, Y. Watai et al., "Oxidative and electrophilic stresses activate Nrf 2 through inhibition of ubiquitination activity of Keap 1," Molecular and Cellular Biology, vol. 26, no. 1, pp. 221-229, 2005.

[31] H. Y. Cho, S. P. Reddy, A. Debiase, M. Yamamoto, and S. R. Kleeberger, "Gene expression profiling of NRF2-mediated protection against oxidative injury," Free Radical Biology and Medicine, vol. 38, no. 3, pp. 325-343, 2005.

[32] B. N. Das, Y. W. Kim, and Y. S. Keum, "Mechanisms of Nrf2/ Keap1-dependent phase II cytoprotective and detoxifying gene expression and potential cellular targets of chemopreventive isothiocyanates," Oxidative Medicine and Cellular Longevity, vol. 2013, Article ID 839409, 7 pages, 2013.
[33] C. H. Jin, Y. K. So, S. N. Han, and J. B. Kim, "Isoegomaketone upregulates heme oxygenase-1 in RAW264.7 cells via ROS/p 38 MAPK/Nrf 2 pathway," Biomolecules \& Therapeutics, vol. 24, no. 5, pp. 510-516, 2016.

[34] W. A. Solis, T. P. Dalton, M. Z. Dieter et al., "Glutamate-cysteine ligase modifier subunit: mouse Gclm gene structure and regulation by agents that cause oxidative stress," Biochemical Pharmacology, vol. 63, no. 9, pp. 1739-1754, 2002.

[35] J. Choi and J.-H. James Ou, "Mechanisms of liver injury. III. Oxidative stress in the pathogenesis of hepatitis C virus," American Journal of Physiology-Gastrointestinal and Liver Physiology, vol. 290, no. 5, pp. G847-G851, 2006.

[36] M. Okuda, K. Li, M. R. Beard et al., "Mitochondrial injury, oxidative stress, and antioxidant gene expression are induced by hepatitis C virus core protein," Gastroenterology, vol. 122, no. 2, pp. 366-375, 2002.

[37] G. Gong, G. Waris, R. Tanveer, and A. Siddiqui, "Human hepatitis $\mathrm{C}$ virus NS5A protein alters intracellular calcium levels, induces oxidative stress, and activates STAT-3 and NF- $\kappa \mathrm{B}$," Proceedings of the National Academy of Sciences, vol. 98, no. 17, pp. 9599-9604, 2001.

[38] T. O. Price, N. Ercal, R. Nakaoke, and W. A. Banks, "HIV-1 viral proteins gp 120 and Tat induce oxidative stress in brain endothelial cells," Brain Research, vol. 1045, no. 1-2, pp. 5763, 2005.

[39] D. Olagnier, S. Peri, C. Steel et al., "Cellular oxidative stress response controls the antiviral and apoptotic programs in dengue virus-infected dendritic cells," PLoS Pathogens, vol. 10, no. 12, article e1004566, 2014.

[40] Y. Jiang, V. L. Scofield, M. Yan et al., "Retrovirus-induced oxidative stress with neuroimmunodegeneration is suppressed by antioxidant treatment with a refined monosodium $\alpha$-luminol (Galavit)," Journal of Virology, vol. 80, no. 9, pp. 4557-4569, 2006.

[41] S. Fukuyama and Y. Kawaoka, "The pathogenesis of influenza virus infections: the contributions of virus and host factors," Current Opinion in Immunology, vol. 23, no. 4, pp. 481486, 2011.

[42] J. Lee, K. Koh, Y. E. Kim, J. H. Ahn, and S. Kim, "Upregulation of Nrf 2 expression by human cytomegalovirus infection protects host cells from oxidative stress," Journal of General Virology, vol. 94, no. Part_7, pp. 1658-1668, 2013.

[43] N. Komaravelli, M. Ansar, R. P. Garofalo, and A. Casola, "Respiratory syncytial virus induces NRF2 degradation through a promyelocytic leukemia protein-ring finger protein 4 dependent pathway," Free Radical Biology and Medicine, vol. 113, pp. 494-504, 2017.

[44] B. Kosmider, E. M. Messier, W. J. Janssen et al., "Nrf 2 protects human alveolar epithelial cells against injury induced by influenza A virus," Respiratory Research, vol. 13, no. 1, p. $43,2012$.

[45] O. Gjyshi, V. Bottero, M. V. Veettil et al., "Kaposi's sarcomaassociated herpesvirus induces Nrf 2 during de novo infection of endothelial cells to create a microenvironment conducive to infection," PLoS Pathogens, vol. 10, no. 10, article e1004460, 2014.

[46] B. Liu, M. Fang, Z. He et al., "Hepatitis B virus stimulates G6PD expression through HBx-mediated Nrf 2 activation," Cell Death \& Disease, vol. 6, no. 11, article e1980, 2015.

[47] Y. L. Cheng, Y. S. Lin, C. L. Chen et al., "Activation of Nrf2 by the dengue virus causes an increase in CLEC5A, which 
enhances TNF- $\alpha$ production by mononuclear phagocytes," Scientific Reports, vol. 6, no. 1, article 32000, 2016.

[48] D. Burdette, M. Olivarez, and G. Waris, "Activation of transcription factor Nrf 2 by hepatitis $C$ virus induces the cell-survival pathway," Journal of General Virology, vol. 91, no. 3, pp. 681-690, 2010.

[49] M. Carvajal-Yepes, K. Himmelsbach, S. Schaedler et al., "Hepatitis C virus impairs the induction of cytoprotective Nrf 2 target genes by delocalization of small Maf proteins," Journal of Biological Chemistry, vol. 286, no. 11, pp. 89418951, 2011.

[50] S. Davinelli, G. Scapagnini, F. Denaro et al., "Altered expression pattern of Nrf 2/HO-1 axis during accelerated-senescence in HIV-1 transgenic rat," Biogerontology, vol. 15, no. 5, pp. 449-461, 2014.

[51] X. Fan, B. S. Staitieh, J. S. Jensen et al., "Activating the Nrf2mediated antioxidant response element restores barrier function in the alveolar epithelium of HIV-1 transgenic rats," American Journal of Physiology-Lung Cellular and Molecular Physiology, vol. 305, no. 3, pp. L267-L277, 2013.

[52] K. H. Peiffer, S. Akhras, K. Himmelsbach et al., "Intracellular accumulation of subviral HBsAg particles and diminished Nrf 2 activation in HBV genotype G expressing cells lead to an increased ROI level," Journal of Hepatology, vol. 62, no. 4, pp. 791-798, 2015.

[53] B. S. Staitieh, L. Ding, W. A. Neveu, P. Spearman, D. M. Guidot, and X. Fan, "HIV-1 decreases Nrf 2/ARE activity and phagocytic function in alveolar macrophages," Journal of Leukocyte Biology, vol. 102, no. 2, pp. 517-525, 2017.

[54] P. K. Y. Wong, W. S. Lynn, Y. C. Lin, W. Choe, and P. H. Yuen, ts1 MoMuLV: A Murine Model of Neuroimmunodegeneration, P. K. Y. Wong and W. S. Lynn, Eds., R. G. Landes, Austin, Texas, 1998.

[55] P. K. Y. Wong and P. H. YuenR. P. Roos, Molecular Basis of Neurologic Disorders Induced by a Mutant, ts1, of Moloney Murine Leukemia Virus, Humana Press, Totowa, New Jersey, 1992.

[56] N. Liu, X. Kuang, H. T. Kim et al., "Possible involvement of both endoplasmic reticulum- and mitochondria-dependent pathways in MoMuLV-ts1-induced apoptosis in astrocytes," Journal of Neurovirology, vol. 10, no. 3, pp. 189-198, 2004.

[57] E. Shikova, Y. C. Lin, K. Saha, B. R. Brooks, and P. K. Wong, "Correlation of specific virus-astrocyte interactions and cytopathic effects induced by ts1, a neurovirulent mutant of Moloney murine leukemia virus," Journal of Virology, vol. 67, no. 3, pp. 1137-1147, 1993.

[58] W. Qiang, X. Kuang, J. Liu et al., "Astrocytes survive chronic infection and cytopathic effects of the ts1 mutant of the retrovirus Moloney murine leukemia virus by upregulation of antioxidant defenses," Journal of Virology, vol. 80, no. 7, pp. 3273-3284, 2006.

[59] A. Antinori, G. Arendt, J. T. Becker et al., "Updated research nosology for HIV-associated neurocognitive disorders," Neurology, vol. 69, no. 18, pp. 1789-1799, 2007.

[60] R. Ellis, D. Langford, and E. Masliah, "HIV and antiretroviral therapy in the brain: neuronal injury and repair," Nature Reviews Neuroscience, vol. 8, no. 1, pp. 33-44, 2007.

[61] J. Karn, “Tackling Tat," Journal of Molecular Biology, vol. 293, no. 2, pp. 235-254, 1999.

[62] H. S. Zhang, X. Y. Chen, T. C. Wu, and F. J. Zhang, "Tanshinone II A inhibits tat-induced HIV-1 transactivation through redox-regulated AMPK/Nampt pathway," Journal of Cellular Physiology, vol. 229, no. 9, pp. 1193-1201, 2014.

[63] H. S. Zhang, H. Y. Li, Y. Zhou, M. R. Wu, and H. S. Zhou, "Nrf 2 is involved in inhibiting Tat-induced HIV-1 long terminal repeat transactivation," Free Radical Biology and Medicine, vol. 47, no. 3, pp. 261-268, 2009.

[64] H. S. Zhang, T. C. Wu, W. W. Sang, and Z. Ruan, "EGCG inhibits Tat-induced LTR transactivation: role of Nrf 2, AKT, AMPK signaling pathway," Life Sciences, vol. 90, no. $19-20$, pp. 747-754, 2012.

[65] R. Mastrantonio, M. Cervelli, S. Pietropaoli, P. Mariottini, M. Colasanti, and T. Persichini, "HIV-Tat induces the Nrf 2/ARE pathway through NMDA receptor-elicited spermine oxidase activation in human neuroblastoma cells," PLoS One, vol. 11, no. 2, article e0149802, 2016.

[66] A. Morris, M. P. George, K. Crothers et al., "HIV and chronic obstructive pulmonary disease: is it worse and why?," Proceedings of the American Thoracic Society, vol. 8, no. 3, pp. 320-325, 2011.

[67] P. C. Joshi, R. Raynor, X. Fan, and D. M. Guidot, "HIV-1transgene expression in rats decreases alveolar macrophage zinc levels and phagocytosis," American Journal of Respiratory Cell and Molecular Biology, vol. 39, no. 2, pp. 218-226, 2008.

[68] X. Fan, P. C. Joshi, M. Koval, and D. M. Guidot, "Chronic alcohol ingestion exacerbates lung epithelial barrier dysfunction in HIV-1 transgenic rats," Alcoholism: Clinical and Experimental Research, vol. 35, no. 10, pp. 1866-1875, 2011.

[69] M. J. Alter, D. Kruszon-Moran, O. V. Nainan et al., "The prevalence of hepatitis $\mathrm{C}$ virus infection in the United States, 1988 through 1994," New England Journal of Medicine, vol. 341, no. 8, pp. 556-562, 1999.

[70] C. Bureau, J. Bernad, N. Chaouche et al., "Nonstructural 3 protein of hepatitis $\mathrm{C}$ virus triggers an oxidative burst in human monocytes via activation of NADPH oxidase," Journal of Biological Chemistry, vol. 276, no. 25, pp. 2307723083, 2001.

[71] K. Machida, K. T.-H. Cheng, C.-K. Lai, K.-S. Jeng, V. M.-H. Sung, and M. M. C. Lai, "Hepatitis $\mathrm{C}$ virus triggers mitochondrial permeability transition with production of reactive oxygen species, leading to DNA damage and STAT3 activation," Journal of Virology, vol. 80, no. 14, pp. 7199-7207, 2006.

[72] R. Yu, C. Chen, Y.-Y. Mo et al., "Activation of mitogenactivated protein kinase pathways induces antioxidant response element-mediated gene expression via a Nrf2dependent mechanism," Journal of Biological Chemistry, vol. 275, no. 51, pp. 39907-39913, 2000.

[73] L. M. Zipper and R. T. Mulcahy, "Inhibition of ERK and p 38 MAP kinases inhibits binding of Nrf 2 and induction of GCS genes," Biochemical and Biophysical Research Communications, vol. 278, no. 2, pp. 484-492, 2000.

[74] H. C. Huang, T. Nguyen, and C. B. Pickett, "Phosphorylation of Nrf 2 at Ser- 40 by protein kinase C regulates antioxidant response element-mediated transcription," Journal of Biological Chemistry, vol. 277, no. 45, pp. 42769-42774, 2002.

[75] P. L. Apopa, X. He, and Q. Ma, "Phosphorylation of Nrf 2 in the transcription activation domain by casein kinase 2 (CK2) is critical for the nuclear translocation and transcription activation function of Nrf 2 in IMR-32 neuroblastoma cells," Journal of Biochemical and Molecular Toxicology, vol. 22, no. 1, pp. 63-76, 2008. 
[76] Z. Goodman and K. Ishak, "Histopathology of hepatitis C virus infection," Seminars in Liver Disease, vol. 15, no. 1, pp. 70-81, 1995.

[77] K. Sugiyama, H. Ebinuma, N. Nakamoto et al., "Prominent steatosis with hypermetabolism of the cell line permissive for years of infection with hepatitis C virus," PLoS One, vol. 9, no. 4, article e94460, 2014.

[78] T. Saito, Y. Ichimura, K. Taguchi et al., "p62/Sqstm1 promotes malignancy of HCV-positive hepatocellular carcinoma through Nrf2-dependent metabolic reprogramming," Nature Communications, vol. 7, article 12030, 2016.

[79] I. Jaspers, K. M. Horvath, W. Zhang, L. E. Brighton, J. L. Carson, and T. L. Noah, "Reduced expression of IRF7 in nasal epithelial cells from smokers after infection with influenza," American Journal of Respiratory Cell and Molecular Biology, vol. 43, no. 3, pp. 368-375, 2010.

[80] I. Jaspers, J. M. Ciencewicki, W. Zhang et al., "Diesel exhaust enhances influenza virus infections in respiratory epithelial cells," Toxicological Sciences, vol. 85, no. 2, pp. 990-1002, 2005.

[81] T. L. Noah, H. Zhou, J. Monaco, K. Horvath, M. Herbst, and I. Jaspers, "Tobacco smoke exposure and altered nasal responses to live attenuated influenza virus," Environmental Health Perspectives, vol. 119, no. 1, pp. 7883, 2011.

[82] M. Phillips, R. N. Cataneo, A. Chaturvedi et al., "Effect of influenza vaccination on oxidative stress products in breath," Journal of Breath Research, vol. 4, no. 2, article 026001, 2010.

[83] Q. Liu, X. Ci, Z. Wen, and L. Peng, "Diosmetin alleviates lipopolysaccharide-induced acute lung injury through activating the Nrf 2 pathway and inhibiting the NLRP3 inflammasome," Biomolecules \& Therapeutics, vol. 26, no. 2, pp. 157-166, 2018.

[84] P. F. Simon, S. McCorrister, P. Hu et al., "Highly pathogenic $\mathrm{H} 5 \mathrm{~N} 1$ and novel H7N9 influenza A viruses induce more profound proteomic host responses than seasonal and pandemic H1N1 strains," Journal of Proteome Research, vol. 14, no. 11, pp. 4511-4523, 2015.

[85] C. B. Hall, "Respiratory syncytial virus: a continuing culprit and conundrum," The Journal of Pediatrics, vol. 135, 2 Part 2, pp. 2-7, 1999.

[86] T. Liu, S. Castro, A. R. Brasier, M. Jamaluddin, R. P. Garofalo, and A. Casola, "Reactive oxygen species mediate virusinduced STAT activation: role of tyrosine phosphatases," Journal of Biological Chemistry, vol. 279, no. 4, pp. 24612469, 2004.

[87] A. Casola, N. Burger, T. Liu, M. Jamaluddin, A. R. Brasier, and R. P. Garofalo, "Oxidant tone regulates RANTES gene expression in airway epithelial cells infected with respiratory syncytial virus role in viral-induced interferon regulatory factor activation," Journal of Biological Chemistry, vol. 276, no. 23, pp. 19715-19722, 2001.

[88] M. Mata, I. Martinez, J. A. Melero, H. Tenor, and J. Cortijo, "Roflumilast inhibits respiratory syncytial virus infection in human differentiated bronchial epithelial cells," PLoS One, vol. 8, no. 7, article e69670, 2013.

[89] N. Komaravelli and A. Casola, "Respiratory viral infections and subversion of cellular antioxidant defenses," Journal of Pharmacogenomics \& Pharmacoproteomics, vol. 5, no. 4, p. $5,2014$.
[90] N. Komaravelli, B. Tian, T. Ivanciuc et al., "Respiratory syncytial virus infection down-regulates antioxidant enzyme expression by triggering deacetylation-proteasomal degradation of Nrf 2," Free Radical Biology and Medicine, vol. 88, no. Part B, pp. 391-403, 2015.

[91] J. Lupberger and E. Hildt, "Hepatitis B virus-induced oncogenesis," World Journal of Gastroenterology, vol. 13, no. 1, pp. 74-81, 2007.

[92] Y. Inami, S. Waguri, A. Sakamoto et al., "Persistent activation of Nrf 2 through p 62 in hepatocellular carcinoma cells," The Journal of Cell Biology, vol. 193, no. 2, pp. 275-284, 2011.

[93] P. Nioi and T. Nguyen, "A mutation of Keap 1 found in breast cancer impairs its ability to repress Nrf 2 activity," Biochemical and Biophysical Research Communications, vol. 362, no. 4, pp. 816-821, 2007.

[94] A. Singh, V. Misra, R. K. Thimmulappa et al., "Dysfunctional KEAP1-NRF2 interaction in non-small-cell lung cancer," PLoS Medicine, vol. 3, no. 10, article e420, 2006.

[95] T. Shibata, A. Kokubu, M. Gotoh et al., "Genetic alteration of Keap 1 confers constitutive Nrf 2 activation and resistance to chemotherapy in gallbladder cancer," Gastroenterology, vol. 135, no. 4, pp. 1358-1368.e4, 2008.

[96] B. J. Jung, H. S. Yoo, S. Shin, Y. J. Park, and S. M. Jeon, "Dysregulation of NRF2 in cancer: from molecular mechanisms to therapeutic opportunities," Biomolecules \& Therapeutics, vol. 26, no. 1, pp. 57-68, 2018.

[97] X. J. Wang, Z. Sun, N. F. Villeneuve et al., "Nrf 2 enhances resistance of cancer cells to chemotherapeutic drugs, the dark side of Nrf 2," Carcinogenesis, vol. 29, no. 6, pp. 1235-1243, 2008.

[98] A. Lau, N. Villeneuve, Z. Sun, P. Wong, and D. Zhang, "Dual roles of Nrf 2 in cancer," Pharmacological Research, vol. 58, no. 5-6, pp. 262-270, 2008.

[99] S. Schaedler, J. Krause, K. Himmelsbach et al., "Hepatitis B virus induces expression of antioxidant response elementregulated genes by activation of Nrf 2," Journal of Biological Chemistry, vol. 285, no. 52, pp. 41074-41086, 2010.

[100] Y. Matsuda, A. Sanpei, T. Wakai et al., "Hepatitis B virus X stimulates redox signaling through activation of ataxia telangiectasia mutated kinase," International Journal of Clinical and Experimental Pathology, vol. 7, no. 5, pp. 2032-2043, 2014.

[101] S. R. Barthel, R. Medvedev, T. Heinrich, S. M. Buchner, N. Kettern, and E. Hildt, "Hepatitis B virus inhibits insulin receptor signaling and impairs liver regeneration via intracellular retention of the insulin receptor," Cellular and Molecular Life Sciences, vol. 73, no. 21, pp. 4121-4140, 2016.

[102] C. P. Marques, M. C.-J. Cheeran, J. M. Palmquist, S. Hu, and J. R. Lokensgard, "Microglia are the major cellular source of inducible nitric oxide synthase during experimental herpes encephalitis," Journal of Neurovirology, vol. 14, no. 3, pp. 229-238, 2008.

[103] S. Hu, W. S. Sheng, S. J. Schachtele, and J. R. Lokensgard, "Reactive oxygen species drive herpes simplex virus (HSV)1 -induced proinflammatory cytokine production by murine microglia," Journal of Neuroinflammation, vol. 8, no. 1, p. $123,2011$.

[104] S. J. Schachtele, S. Hu, M. R. Little, and J. R. Lokensgard, "Herpes simplex virus induces neural oxidative damage via microglial cell Toll-like receptor-2," Journal of Neuroinflammation, vol. 7, no. 1, p. 35, 2010. 
[105] S. J. Schachtele, S. Hu, and J. R. Lokensgard, "Modulation of experimental herpes encephalitis-associated neurotoxicity through sulforaphane treatment," PLoS One, vol. 7, no. 4, article e36216, 2012.

[106] C. Tilton, A. J. Clippinger, T. Maguire, and J. C. Alwine, "Human cytomegalovirus induces multiple means to combat reactive oxygen species," Journal of Virology, vol. 85, no. 23, pp. 12585-12593, 2011.

[107] Y. Chang, E. Cesarman, M. Pessin et al., "Identification of herpesvirus-like DNA sequences in AIDS-associated Kaposi's sarcoma," Science, vol. 266, no. 5192, pp. 1865-1869, 1994.

[108] E. Cesarman, Y. Chang, P. S. Moore, J. W. Said, and D. M. Knowles, "Kaposi's sarcoma-associated herpesvirus-like DNA sequences in AIDS-related body-cavity-based lymphomas," New England Journal of Medicine, vol. 332, no. 18, pp. 1186-1191, 1995.

[109] S. Bhatt, P. W. Gething, O. J. Brady et al., "The global distribution and burden of dengue," Nature, vol. 496, no. 7446, pp. 504-507, 2013.

[110] A. Wilder-Smith, E. E. Ooi, S. G. Vasudevan, and D. J. Gubler, "Update on dengue: epidemiology, virus evolution, antiviral drugs, and vaccine development," Current Infectious Disease Reports, vol. 12, no. 3, pp. 157-164, 2010.

[111] B. L. Ligon, "Outbreak of Marburg hemorrhagic fever in Angola: a review of the history of the disease and its biological aspects," Seminars in Pediatric Infectious Diseases, vol. 16, no. 3, pp. 219-224, 2005.

[112] M. R. Edwards, B. Johnson, C. E. Mire et al., “The Marburg virus VP24 protein interacts with Keap 1 to activate the cytoprotective antioxidant response pathway," Cell Reports, vol. 6, no. 6, pp. 1017-1025, 2014.

[113] A. Page, V. A. Volchkova, S. P. Reid et al., "Marburgvirus hijacks Nrf2-dependent pathway by targeting Nrf2-negative regulator Keap1," Cell Reports, vol. 6, no. 6, pp. 1026-1036, 2014.

[114] B. Johnson, J. Li, J. Adhikari et al., "Dimerization controls Marburg virus VP24-dependent modulation of host antioxidative stress responses," Journal of Molecular Biology, vol. 428, no. 17, pp. 3483-3494, 2016.

[115] Z. Liu, Y. Teng, X. Xie et al., "Development and evaluation of a one-step loop-mediated isothermal amplification for detection of spring viraemia of carp virus," Journal of Applied Microbiology, vol. 105, no. 4, pp. 1220-1226, 2008.

[116] J. Shao, J. Huang, Y. Guo et al., "Up-regulation of nuclear factor E2-related factor 2 ( $\mathrm{Nrf} 2)$ represses the replication of SVCV," Fish \& Shellfish Immunology, vol. 58, pp. 474-482, 2016.

[117] Y. Yang, J. Huang, L. Li et al., "Up-regulation of nuclear factor E2-related factor 2 upon SVCV infection," Fish \& Shellfish Immunology, vol. 40, no. 1, pp. 245-252, 2014.

[118] J. Sejvar, "Clinical manifestations and outcomes of West Nile virus infection,” Viruses, vol. 6, no. 2, pp. 606-623, 2014.

[119] F. Mostashari, M. L. Bunning, P. T. Kitsutani et al., "Epidemic West Nile encephalitis, New York, 1999: results of a household-based seroepidemiological survey," The Lancet, vol. 358, no. 9278, pp. 261-264, 2001.

[120] P. J. Carson, S. M. Borchardt, B. Custer et al., "Neuroinvasive disease and West Nile virus infection, North Dakota, USA, 1999-2008," Emerging Infectious Diseases, vol. 18, no. 4, pp. 684-686, 2012.
[121] M. Basu, S. C. Courtney, and M. A. Brinton, "Arseniteinduced stress granule formation is inhibited by elevated levels of reduced glutathione in West Nile virus-infected cells," PLOS Pathogens, vol. 13, no. 2, article e1006240, 2017.

[122] S. P. Chen, H. L. Yang, G. M. Her et al., "Betanodavirus induces phosphatidylserine exposure and loss of mitochondrial membrane potential in secondary necrotic cells, both of which are blocked by bongkrekic acid," Virology, vol. 347, no. 2, pp. 379-391, 2006.

[123] C. W. Chang, Y. C. Su, G. M. Her, C. F. Ken, and J. R. Hong, "Betanodavirus induces oxidative stress-mediated cell death that prevented by anti-oxidants and zfcatalase in fish cells," PLoS One, vol. 6, no. 10, article e25853, 2011.

[124] H.-Y. Cho, A. E. Jedlicka, S. P. M. Reddy et al., "Role of NRF2 in protection against hyperoxic lung injury in mice," American Journal of Respiratory Cell and Molecular Biology, vol. 26, no. 2, pp. 175-182, 2002.

[125] T. Iizuka, Y. Ishii, K. Itoh et al., "Nrf2-deficient mice are highly susceptible to cigarette smoke-induced emphysema," Genes Cells, vol. 10, no. 12, pp. 1113-1125, 2005.

[126] T. Rangasamy, C. Y. Cho, R. K. Thimmulappa et al., "Genetic ablation of Nrf 2 enhances susceptibility to cigarette smokeinduced emphysema in mice," Journal of Clinical Investigation, vol. 114, no. 9, pp. 1248-1259, 2004.

[127] Y. Yageta, Y. Ishii, Y. Morishima et al., "Role of Nrf 2 in host defense against influenza virus in cigarette smoke-exposed mice," Journal of Virology, vol. 85, no. 10, pp. 4679-4690, 2011.

[128] M. V. Nelyubov, "Cytokins in the pathogenesis of astrakhan spotted fever and North Asian scrub typhus: problems of immunocorrection," Bulletin of Experimental Biology and Medicine, vol. 134, no. 2, pp. 165-167, 2002.

[129] V. L. Scofield, M. Yan, X. Kuang, S.-J. Kim, D. Crunk, and P. K. Y. Wong, "The drug monosodium luminol (GVT) preserves thymic epithelial cell cytoarchitecture and allows thymocyte survival in mice infected with the T cell-tropic, cytopathic retrovirus ts1," Immunology Letters, vol. 122, no. 2, pp. 159-169, 2009.

[130] V. L. Scofield, M. Yan, X. Kuang, S.-J. Kim, and P. K. Y. Wong, "The drug monosodium luminol (GVT) preserves crypt-villus epithelial organization and allows survival of intestinal T cells in mice infected with the ts1 retrovirus," Immunology Letters, vol. 122, no. 2, pp. 150-158, 2009.

[131] X. Kuang, V. L. Scofield, M. Yan, G. Stoica, N. Liu, and P. K. Y. Wong, "Attenuation of oxidative stress, inflammation and apoptosis by minocycline prevents retrovirus-induced neurodegeneration in mice," Brain Research, vol. 1286, pp. 174184, 2009.

[132] S. Wolfram, "Effects of green tea and EGCG on cardiovascular and metabolic health," Journal of the American College of Nutrition, vol. 26, no. 4, pp. 373S-388S, 2007.

[133] D. N. Syed, F. Afaq, M. H. Kweon et al., "Green tea polyphenol EGCG suppresses cigarette smoke condensate-induced NF- $\kappa \mathrm{B}$ activation in normal human bronchial epithelial cells," Oncogene, vol. 26, no. 5, pp. 673-682, 2007.

[134] J. D. Lambert and R. J. Elias, "The antioxidant and prooxidant activities of green tea polyphenols: a role in cancer prevention," Archives of Biochemistry and Biophysics, vol. 501, no. 1, pp. 65-72, 2010. 
[135] N. Khan, F. Afaq, M. Saleem, N. Ahmad, and H. Mukhtar, "Targeting multiple signaling pathways by green tea polyphenol (-)-epigallocatechin-3-gallate," Cancer Research, vol. 66, no. 5, pp. 2500-2505, 2006.

[136] I. Hauber, H. Hohenberg, B. Holstermann, W. Hunstein, and J. Hauber, "The main green tea polyphenol epigallocatechin3-gallate counteracts semen-mediated enhancement of HIV infection," Proceedings of the National Academy of Sciences, vol. 106, no. 22, pp. 9033-9038, 2009.

[137] C. L. Nance, E. B. Siwak, and W. T. Shearer, "Preclinical development of the green tea catechin, epigallocatechin gallate, as an HIV-1 therapy," Journal of Allergy and Clinical Immunology, vol. 123, no. 2, pp. 459-465, 2009.

[138] S. Xu and P. Liu, "Tanshinone II-A: new perspectives for old remedies," Expert Opinion on Therapeutic Patents, vol. 23, no. 2, pp. 149-153, 2012.

[139] X. H. Tian and J. H. Wu, "Tanshinone derivatives: a patent review (January 2006-September 2012)," Expert Opinion on Therapeutic Patents, vol. 23, no. 1, pp. 19-29, 2012.

[140] P. Gupta, B. Kim, S. H. Kim, and S. K. Srivastava, "Molecular targets of isothiocyanates in cancer: recent advances," Molecular Nutrition \& Food Research, vol. 58, no. 8, pp. 1685-1707, 2014.

[141] M. C. Myzak and R. H. Dashwood, "Chemoprotection by sulforaphane: keep one eye beyond Keap 1," Cancer Letters, vol. 233, no. 2, pp. 208-218, 2006.

[142] K. Itoh, T. Chiba, S. Takahashi et al., "An Nrf 2/small Maf heterodimer mediates the induction of phase II detoxifying enzyme genes through antioxidant response elements," Biochemical and Biophysical Research Communications, vol. 236, no. 2, pp. 313-322, 1997.

[143] J. D. Hayes and M. McMahon, "Molecular basis for the contribution of the antioxidant responsive element to cancer chemoprevention," Cancer Letters, vol. 174, no. 2, pp. 103$113,2001$.

[144] C. E. Guerrero-Beltran, P. Mukhopadhyay, B. Horvath et al., "Sulforaphane, a natural constituent of broccoli, prevents cell death and inflammation in nephropathy," The Journal of Nutritional Biochemistry, vol. 23, no. 5, pp. 494-500, 2012.

[145] A. K. M. Furuya, H. J. Sharifi, R. M. Jellinger, P. Cristofano, B. Shi, and C. M. C. de Noronha, "Sulforaphane inhibits HIV infection of macrophages through Nrf 2," PLOS Pathogens, vol. 12, no. 4, article e1005581, 2016.

[146] S. A. Cross, D. R. Cook, A. W. S. Chi et al., "Dimethyl fumarate, an immune modulator and inducer of the antioxidant response, suppresses HIV replication and macrophagemediated neurotoxicity: a novel candidate for HIV neuroprotection," The Journal of Immunology, vol. 187, no. 10, pp. 5015-5025, 2011.

[147] S. W. Ryter, D. Morse, and A. M. K. Choi, "Carbon monoxide and bilirubin: potential therapies for pulmonary/vascular injury and disease," American Journal of Respiratory Cell and Molecular Biology, vol. 36, no. 2, pp. 175-182, 2007.

[148] Z. Zhu, A. T. Wilson, B. A. Luxon et al., "Biliverdin inhibits hepatitis $\mathrm{C}$ virus nonstructural 3/4A protease activity: mechanism for the antiviral effects of heme oxygenase?," Hepatology, vol. 52, no. 6, pp. 1897-1905, 2010.

[149] E. Lehmann, W. H. El-Tantawy, M. Ocker et al., "The heme oxygenase 1 product biliverdin interferes with hepatitis $\mathrm{C}$ virus replication by increasing antiviral interferon response," Hepatology, vol. 51, no. 2, pp. 398-404, 2010.
[150] W. C. Chen, C. K. Tseng, C. K. Lin et al., "Lucidone suppresses dengue viral replication through the induction of heme oxygenase-1," Virulence, vol. 9, no. 1, pp. 588-603, 2018.

[151] J. X. Chen, H. J. Xue, W. C. Ye et al., "Activity of andrographolide and its derivatives against influenza virus in vivo and in vitro," Biological \& Pharmaceutical Bulletin, vol. 32, no. 8, pp. 1385-1391, 2009.

[152] K. Maiti, K. Mukherjee, V. Murugan, B. P. Saha, and P. K. Mukherjee, "Enhancing bioavailability and hepatoprotective activity of andrographolide from Andrographis paniculata, a well-known medicinal food, through its herbosome," Journal of the Science of Food and Agriculture, vol. 90, no. 1, pp. 43-51, 2010.

[153] J. C. Lee, C. K. Tseng, K. C. Young et al., “Andrographolide exerts anti-hepatitis $\mathrm{C}$ virus activity by up-regulating haeme oxygenase-1 via the $\mathrm{p} 38$ MAPK/Nrf 2 pathway in human hepatoma cells," British Journal of Pharmacology, vol. 171, no. 1, pp. 237-252, 2014.

[154] F. Gueler, J. K. Park, S. Rong et al., "Statins attenuate ischemia-reperfusion injury by inducing heme oxygenase-1 in infiltrating macrophages," The American Journal of Pathology, vol. 170, no. 4, pp. 1192-1199, 2007.

[155] T. S. Lee, C. C. Chang, Y. Zhu, and J. Y. Shyy, "Simvastatin induces heme oxygenase-1: a novel mechanism of vessel protection," Circulation, vol. 110, no. 10, pp. 1296-1302, 2004.

[156] N. Grosser, A. Hemmerle, G. Berndt et al., "The antioxidant defense protein heme oxygenase 1 is a novel target for statins in endothelial cells," Free Radical Biology and Medicine, vol. 37, no. 12, pp. 2064-2071, 2004.

[157] A. Wuestenberg, J. Kah, K. Singethan et al., "Matrix conditions and KLF2-dependent induction of heme oxygenase-1 modulate inhibition of HCV replication by fluvastatin," PLoS One, vol. 9, no. 5, article e96533, 2014.

[158] J. S. Yu, W. C. Chen, C. K. Tseng et al., "Sulforaphane suppresses hepatitis $\mathrm{C}$ virus replication by up-regulating heme oxygenase-1 expression through PI3K/Nrf2 pathway," PLoS One, vol. 11, no. 3, article e0152236, 2016.

[159] G. S. Youn, D. J. Kwon, S. M. Ju et al., "Celastrol ameliorates HIV-1 Tat-induced inflammatory responses via NF-kappaB and AP-1 inhibition and heme oxygenase-1 induction in astrocytes," Toxicology and Applied Pharmacology, vol. 280, no. 1, pp. 42-52, 2014.

[160] J. Y. Lee, B. H. Lee, N. D. Kim, and J. Y. Lee, "Celastrol blocks binding of lipopolysaccharides to a Toll-like receptor 4 /myeloid differentiation factor 2 complex in a thiol-dependent manner," Journal of Ethnopharmacology, vol. 172, pp. 254260, 2015.

[161] S. M. Ju, G. S. Youn, Y. S. Cho, S. Y. Choi, and J. Park, “Celastrol ameliorates cytokine toxicity and pro-inflammatory immune responses by suppressing NF- $\kappa \mathrm{B}$ activation in RINm5F beta cells," BMB Reports, vol. 48, no. 3, pp. 172$177,2015$.

[162] C. K. Tseng, S. P. Hsu, C. K. Lin, Y. H. Wu, J. C. Lee, and K. C. Young, "Celastrol inhibits hepatitis $\mathrm{C}$ virus replication by upregulating heme oxygenase-1 via the JNK MAPK/Nrf 2 pathway in human hepatoma cells," Antiviral Research, vol. 146, pp. 191-200, 2017.

[163] M. J. Kesic, S. O. Simmons, R. Bauer, and I. Jaspers, "Nrf2 expression modifies influenza A entry and replication in nasal epithelial cells," Free Radical Biology and Medicine, vol. 51, no. 2, pp. 444-453, 2011. 
[164] S. Sueyoshi, Y. Miyata, Y. Masumoto et al., "Reduced airway inflammation and remodeling in parallel with mucin 5AC protein expression decreased by s-carboxymethylcysteine, a mucoregulant, in the airways of rats exposed to sulfur dioxide," International Archives of Allergy and Immunology, vol. 134, no. 4, pp. 273-280, 2004.

[165] K. Takeda, N. Miyahara, T. Kodama et al., "S-Carboxymethylcysteine normalises airway responsiveness in sensitised and challenged mice," European Respiratory Journal, vol. 26, no. 4, pp. 577-585, 2005.

[166] Y. Yageta, Y. Ishii, Y. Morishima et al., "Carbocisteine reduces virus-induced pulmonary inflammation in mice exposed to cigarette smoke," American Journal of Respiratory Cell and Molecular Biology, vol. 50, no. 5, pp. 963-973, 2014.

[167] T. L. Noah, H. Zhang, H. Zhou et al., "Effect of broccoli sprouts on nasal response to live attenuated influenza virus in smokers: a randomized, double-blind study," PLoS One, vol. 9, no. 6, article e98671, 2014.

[168] S. Ji, R. Li, Q. Wang et al., "Anti-H1N1 virus, cytotoxic and Nrf 2 activation activities of chemical constituents from Scutellaria baicalensis," Journal of Ethnopharmacology, vol. 176, pp. 475-484, 2015.

[169] S. H. Lim, T. Y. Ha, S. R. Kim, J. Ahn, H. J. Park, and S. Kim, "Ethanol extract of Psoralea corylifolia L. and its main constituent, bakuchiol, reduce bone loss in ovariectomised Sprague-Dawley rats," British Journal of Nutrition, vol. 101, no. 7, pp. 1031-1039, 2009.

[170] Z. Chen, K. Jin, L. Gao et al., "Anti-tumor effects of bakuchiol, an analogue of resveratrol, on human lung adenocarcinoma A549 cell line," European Journal of Pharmacology, vol. 643, no. 2-3, pp. 170-179, 2010.

[171] E. Jourdan, A. Fauger, M. Sayag, and K. Poláková, “A dermocosmetic containing bakuchiol, Ginkgo biloba extract and mannitol improves the efficacy of adapalene in patients with acne vulgaris: result from a controlled randomized trial," Clinical, Cosmetic and Investigational Dermatology, vol. 8, pp. 187-191, 2015.

[172] M. Shoji, Y. Arakaki, T. Esumi et al., "Bakuchiol is a phenolic isoprenoid with novel enantiomer-selective anti-influenza A virus activity involving Nrf 2 activation," Journal of Biological Chemistry, vol. 290, no. 46, pp. 28001-28017, 2015.

[173] S. Ji, Z. Li, W. Song et al., "Bioactive constituents of Glycyrrhiza uralensis (licorice): discovery of the effective components of a traditional herbal medicine," Journal of Natural Products, vol. 79, no. 2, pp. 281-292, 2016.

[174] Y. W. He, C. Z. Dong, J. Y. Zhao, L. L. Ma, Y. H. Li, and H. A. Aisa, "1,2,3-Triazole-containing derivatives of rupestonic acid: click-chemical synthesis and antiviral activities against influenza viruses," European Journal of Medicinal Chemistry, vol. 76, pp. 245-255, 2014.

[175] J. Yong, C. Lu, and H. A. Aisa, "Advances in studies on the rupestonic acid derivatives as anti-influenza agents," Mini-Reviews in Medicinal Chemistry, vol. 13, no. 2, pp. 310-315, 2013.

[176] L. L. Ma, H. Q. Wang, P. Wu et al., "Rupestonic acid derivative YZH-106 suppresses influenza virus replication by activation of heme oxygenase-1-mediated interferon response," Free Radical Biology and Medicine, vol. 96, pp. 347-361, 2016.

[177] J. Yin, L. Ma, H. Wang et al., "Chinese herbal medicine compound Yi-Zhi-Hao pellet inhibits replication of influenza virus infection through activation of heme oxygenase-1," Acta Pharmaceutica Sinica B, vol. 7, no. 6, pp. 630-637, 2017.

[178] J. Xue, F. Chen, J. Wang et al., "Emodin protects against concanavalin A-induced hepatitis in mice through inhibiting activation of the $\mathrm{p} 38$ MAPK-NF- $\kappa \mathrm{B}$ signaling pathway," Cellular Physiology and Biochemistry, vol. 35, no. 4, pp. 15571570, 2015.

[179] S. M. Ahn, Y. R. Kim, H. N. Kim, H. K. Shin, and B. T. Choi, "Beneficial effects of Polygonum multiflorum on hippocampal neuronal cells and mouse focal cerebral ischemia," The American Journal of Chinese Medicine, vol. 43, no. 4, pp. 637-651, 2015.

[180] J. P. Dai, Q. W. Wang, Y. Su et al., "Emodin inhibition of influenza A virus replication and influenza viral pneumonia via the Nrf2, TLR4, p38/JNK and NF-kappaB pathways," Molecules, vol. 22, no. 10, 2017.

[181] A. Barzegar and A. A. Moosavi-Movahedi, "Intracellular ROS protection efficiency and free radical-scavenging activity of curcumin," PLoS One, vol. 6, no. 10, article e26012, 2011.

[182] R. A. Sharma, H. R. McLelland, K. A. Hill et al., "Pharmacodynamic and pharmacokinetic study of oral Curcuma extract in patients with colorectal cancer," Clinical Cancer Research, vol. 7, no. 7, pp. 1894-1900, 2001.

[183] J. Dai, L. Gu, Y. Su et al., "Inhibition of curcumin on influenza A virus infection and influenzal pneumonia via oxidative stress, TLR2/4, p38/JNK MAPK and NF- $\kappa$ B pathways," International Immunopharmacology, vol. 54, pp. 177-187, 2018.

[184] Y. Aoki, H. Sato, N. Nishimura, S. Takahashi, K. Itoh, and M. Yamamoto, "Accelerated DNA adduct formation in the lung of the Nrf2 knockout mouse exposed to diesel exhaust," Toxicology and Applied Pharmacology, vol. 173, no. 3, pp. 154-160, 2001.

[185] U. Protzer, S. Seyfried, M. Quasdorff et al., “Antiviral activity and hepatoprotection by heme oxygenase- 1 in hepatitis B virus infection," Gastroenterology, vol. 133, no. 4, pp. 1156$1165,2007$.

[186] H. M. Zhang, H. Dai, P. J. Hanson et al., "Antiviral activity of an isatin derivative via induction of PERK-Nrf2-mediated suppression of cap-independent translation," ACS Chemical Biology, vol. 9, no. 4, pp. 1015-1024, 2014.

[187] T. Wang, J. Zhang, A. Xiao, W. Liu, Y. Shang, and J. An, "Melittin ameliorates CVB3-induced myocarditis via activation of the HDAC2-mediated GSK-3 $\beta$ /Nrf2/ARE signaling pathway," Biochemical and Biophysical Research Communications, vol. 480, no. 1, pp. 126-131, 2016.

[188] H. Huang, B. Falgout, K. Takeda, K. M. Yamada, and S. Dhawan, "Nrf2-dependent induction of innate host defense via heme oxygenase-1 inhibits Zika virus replication," Virology, vol. 503, pp. 1-5, 2017.

[189] C. J. Breitbach, T. Reid, J. Burke, J. C. Bell, and D. H. Kirn, "Navigating the clinical development landscape for oncolytic viruses and other cancer therapeutics: no shortcuts on the road to approval," Cytokine \& Growth Factor Reviews, vol. 21, no. 2-3, pp. 85-89, 2010.

[190] K. Rowan, "Oncolytic viruses move forward in clinical trials," JNCI Journal of the National Cancer Institute, vol. 102, no. 9, pp. 590-595, 2010.

[191] S. J. Russell, K. W. Peng, and J. C. Bell, "Oncolytic virotherapy," Nature Biotechnology, vol. 30, no. 7, pp. 658-670, 2012.

[192] M. C. Dal Canto, B. S. Kim, S. D. Miller, and R. W. Melvold, "Theiler's murine encephalomyelitis virus (TMEV)-induced 
demyelination: a model for human multiple sclerosis," Methods, vol. 10, no. 3, pp. 453-461, 1996.

[193] K. Kobayashi, H. Tomiki, Y. Inaba, M. Ichikawa, B. S. Kim, and C. S. Koh, "Dimethyl fumarate suppresses Theiler's murine encephalomyelitis virus-induced demyelinating disease by modifying the Nrf2-Keap1 pathway," International Immunology, vol. 27, no. 7, pp. 333-344, 2015.

[194] M. J. Tunon, S. Sanchez-Campos, J. Garcia-Ferreras, M. Alvarez, F. Jorquera, and J. Gonzalez-Gallego, "Rabbit hemorrhagic viral disease: characterization of a new animal model of fulminant liver failure," Journal of Laboratory and Clinical Medicine, vol. 141, no. 4, pp. 272-278, 2003.

[195] I. Crespo, B. S. Miguel, A. Laliena et al., "Melatonin prevents the decreased activity of antioxidant enzymes and activates nuclear erythroid 2-related factor 2 signaling in an animal model of fulminant hepatic failure of viral origin," Journal of Pineal Research, vol. 49, no. 2, pp. 193-200, 2010.

[196] J. Segales, "Porcine circovirus type 2 (PCV2) infections: clinical signs, pathology and laboratory diagnosis," Virus Research, vol. 164, no. 1-2, pp. 10-19, 2012.

[197] F. Gan, Z. Hu, Y. Huang et al., "Overexpression of pig selenoprotein S blocks OTA-induced promotion of PCV2 replication by inhibiting oxidative stress and p 38 phosphorylation in PK15 cells," Oncotarget, vol. 7, no. 15, pp. 20469-20485, 2016. 


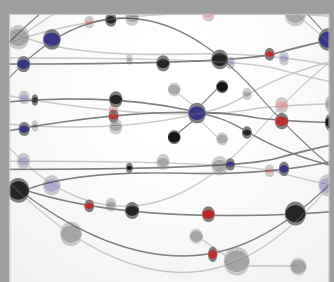

The Scientific World Journal
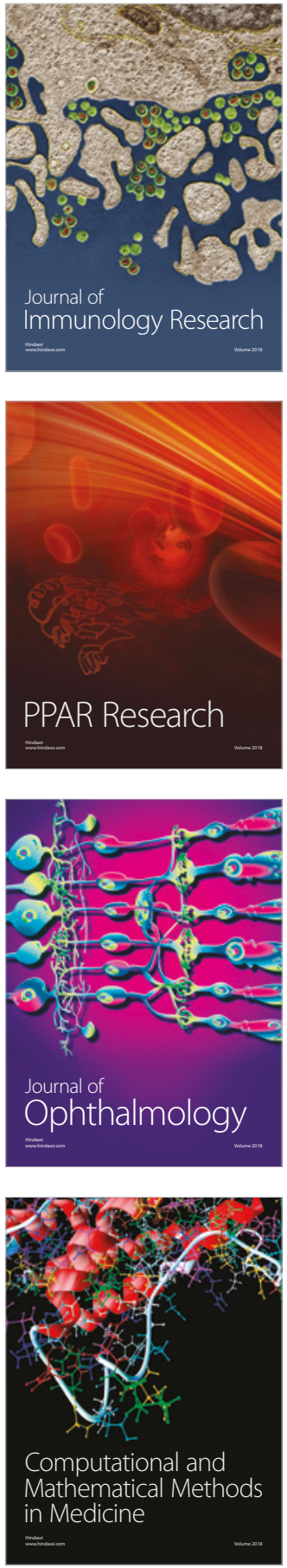

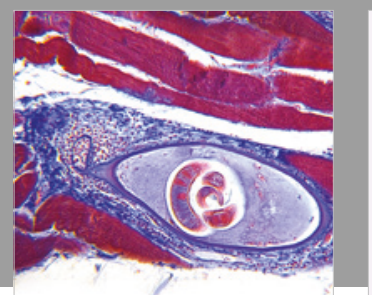

Gastroenterology Research and Practice

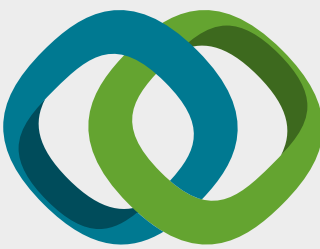

\section{Hindawi}

Submit your manuscripts at

www.hindawi.com
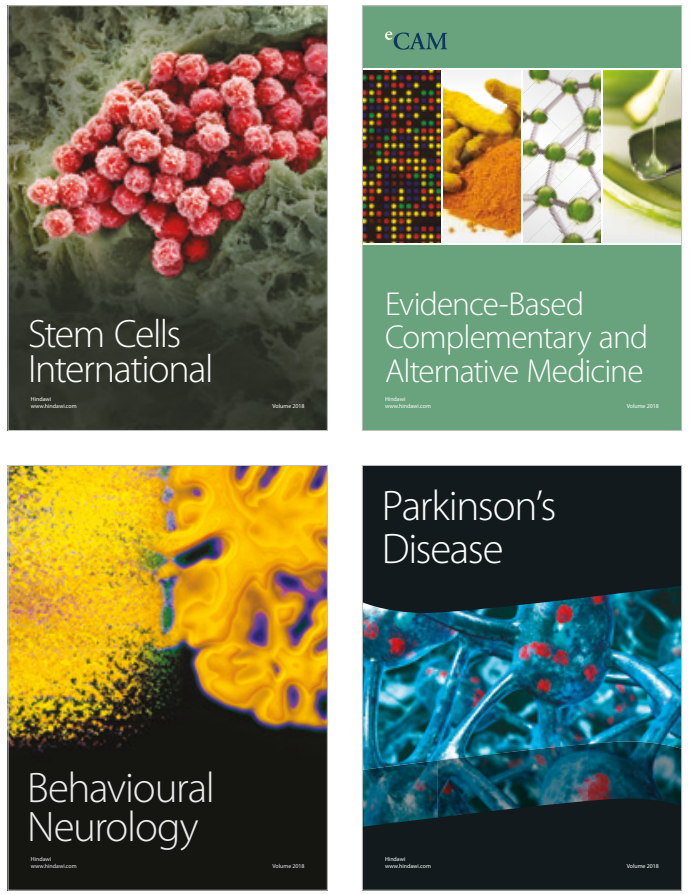

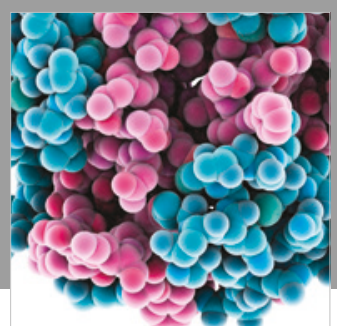

ournal of

Diabetes Research

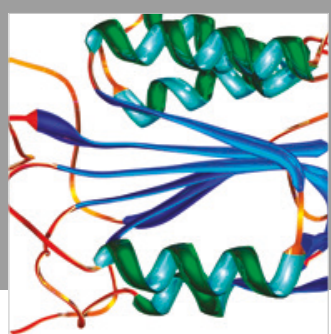

Disease Markers
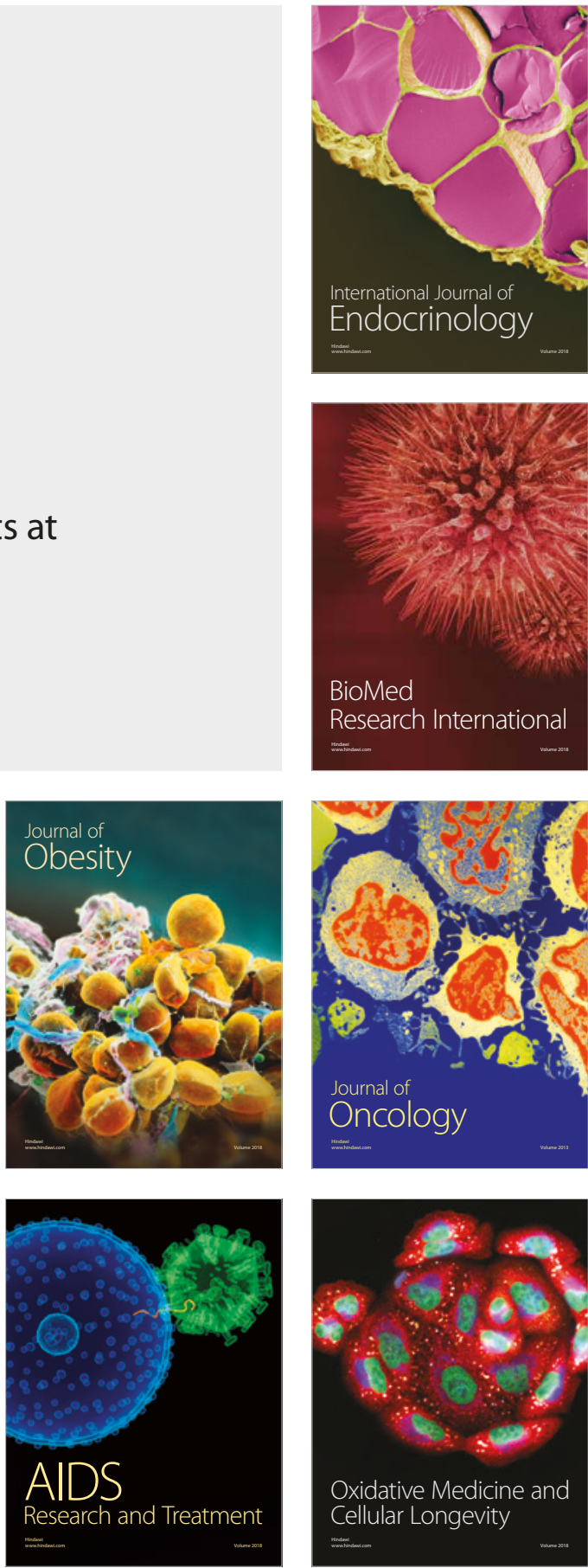